
PERFORMANCE AND AESTHETIC EFEETS

\section{OF DAYLIGHT}

by

JUAN GONZALO SANTAMARIA

B.S. (Chemical), Universidad Pontificia Bolivariana Medellin, Colombia, 1976

A MASTER'S THESIS

submitted in partial fulfillment of the requirements for the degree

MASTER OF SCIENCE

Department of Industrial Engineering

KANSAS STATE UNIVERSTTY

Manhattan, Kansas

1979

Approved by:

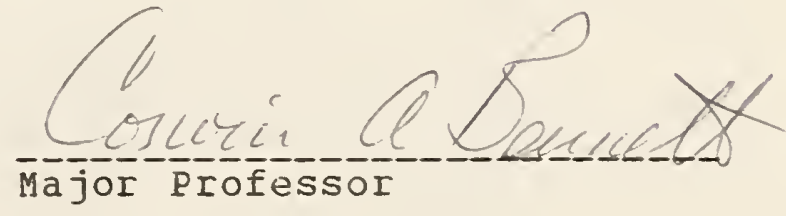




\section{ACKNOWLEDGEMENT}

$5 \times 64$

C.2

I want to express my gratitude to all of the people whcse cooperation made this research possible; especially to those who lent me their time as subjects, and others directly involved at different stages.

In particular I want to thank Dr. Corwin A. Bennett for his guidance and advice, Dr. R. M. Rubison and Mr. J. Rahenkamp from the Kansas state Department of Statistics for their valuable help in the analysis of the data. 
CONTENT

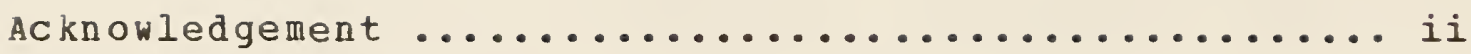

List cf Figures............................. iv

List cf Tables .............................. v

INTROLUCTION $\ldots \ldots \ldots \ldots \ldots \ldots \ldots \ldots \ldots \ldots \ldots \ldots \ldots \ldots \ldots \ldots$

caylight..............................

Eerformance ........................... 7

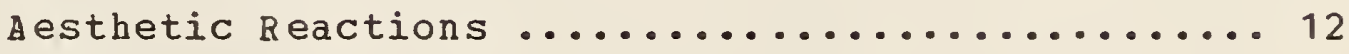

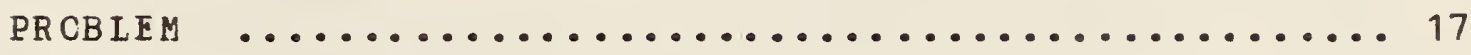

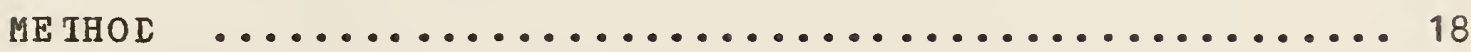

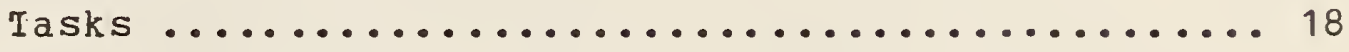

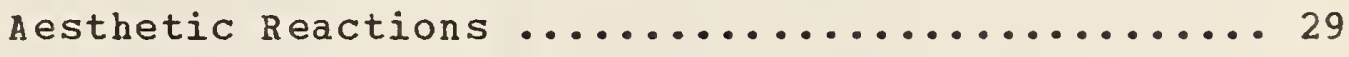

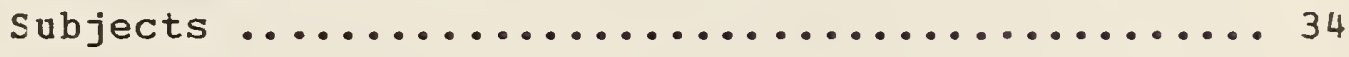

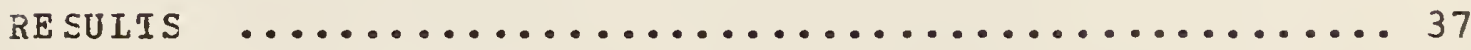

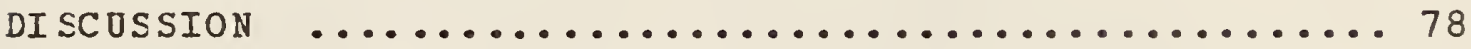

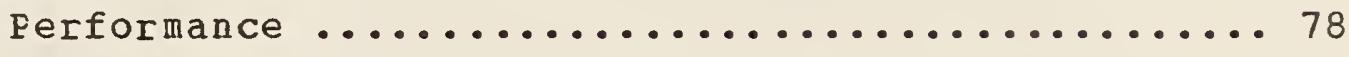

Aesthetics ............................ 80

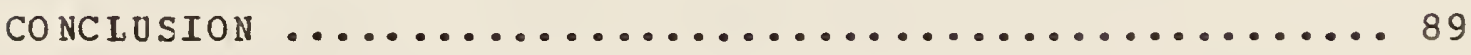

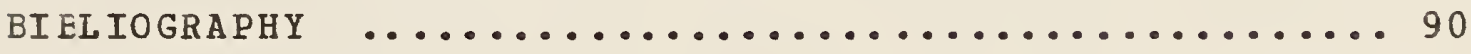




\section{LIST OF FIGURES}

Figure 1 - Kruithoff's principle - Relationship of

cclor temperature to luminance levels .......... 16

Figure 2 - Instructions given to the subjects........ 19

Figure 3 - Letter transformations for the

proofreading paragraphs ................... 27

Pigure 4 - Graph used in the graph reading task ...... 28

Figure 5 - Sampling form containing the semantic

scales ................................. 31

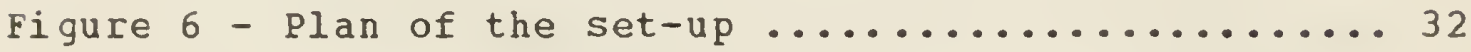

Figure 7 - view of the set-up with the booth ........33

Figure 8 - Means of times to perform .............4 1

Figure 9 - Relationship of the Blue/Red ratio

to illumination level .................... 42

Figure 10 - Means of subject's difficulty ratings .... 46

Figure 11 - Proofreading time vs. illumination

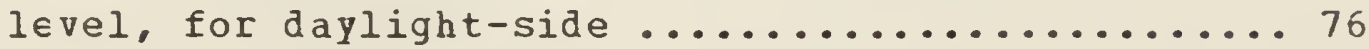

Figure 12 - proofreading ratings vs - illumination

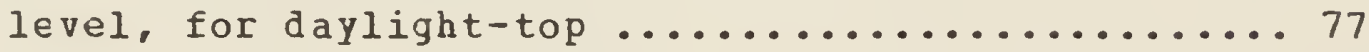

Figure 13 - Factors and scales ..................81 
LIST OF TABLES

Tatle 1 - Needle numbers and dimensions of

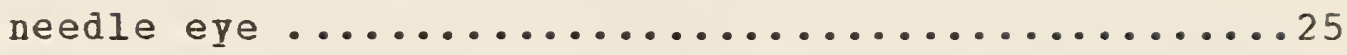

Tatle 2 - Biographical data of the subjects .........36 Table 3 - Needle probing: time to perform,

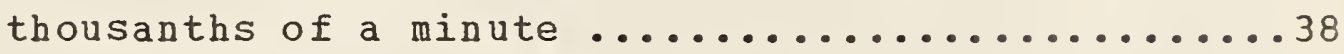

Table 4 - Graph reading: time to perform,

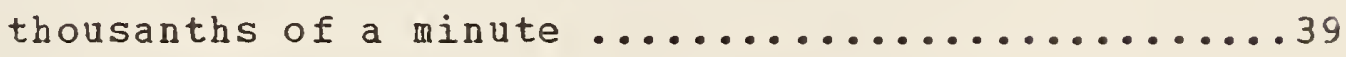

Table 5 - Proofreading: time to perform,

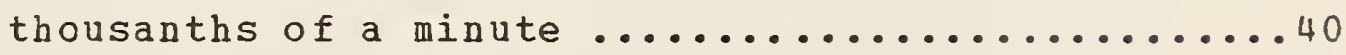

Takle 6 - Needle probing: subject's difficultI

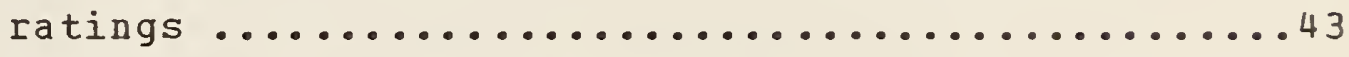

Tatle 7 - Graph reading: subject's difficulty ratings .44 ratle 8 - Proofreading: subject's difficulty ratings ..45 Table 9 - Semantic differential ratings for

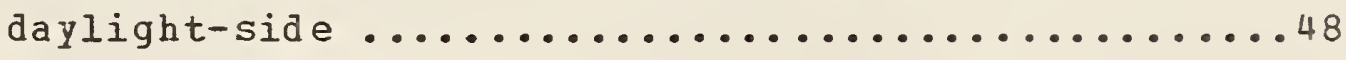

Takle 10 - Semantic differential ratings for

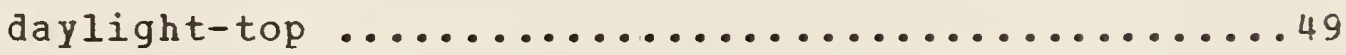

Tatle 11 - Semantic differential ratings for

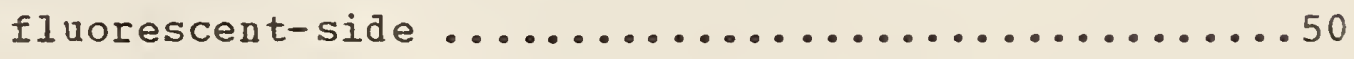

Table 12 - semantic differential ratings for

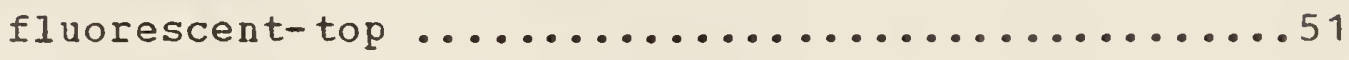

Table 13 - Analysis of covariance on time to

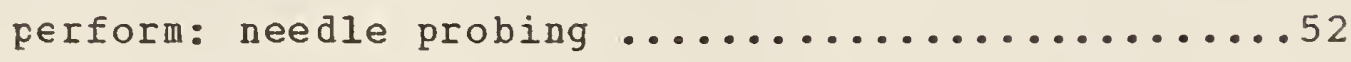

Takle 14 - Analysis of covariance on time to

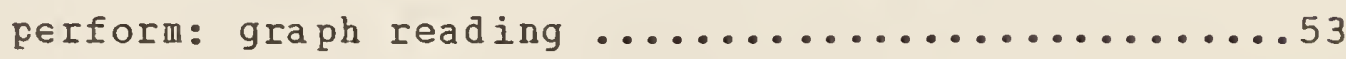


Takle 15 - Analysis of covariance on time to

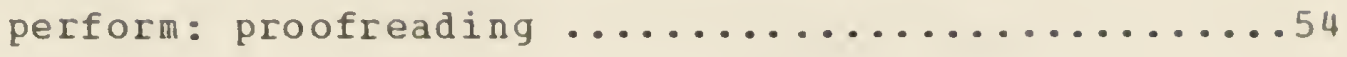
Tatle 16 - Analysis of covariance on subject's

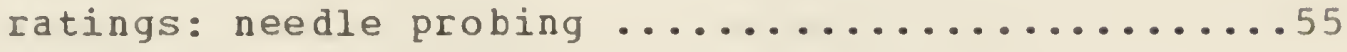
Tatle 17 - Analysis of covariance on subject's

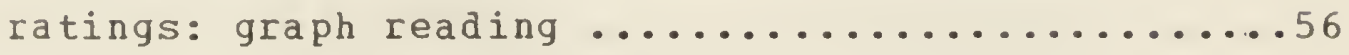
Tatle 18 - Analysis of covariance on subject's

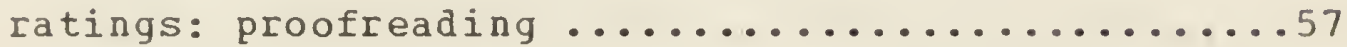
Tatle 19 - Correlation matrix of the semantic

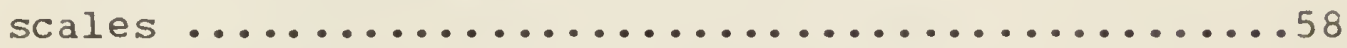

Tatle 20 - Factor pattern and explained variance.....59 Tatle 21 Analysis of covariance on factors:

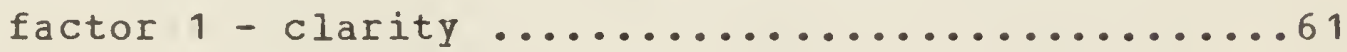

Tatle 22 - Analysis of covariance on factors

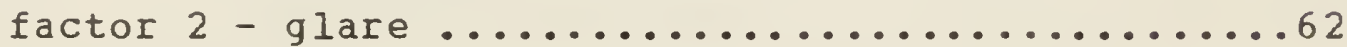

Tatle 23 - Analysis of covariance on factors

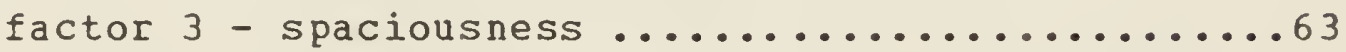

Tatle 24 - Analysis of covariance on factors:

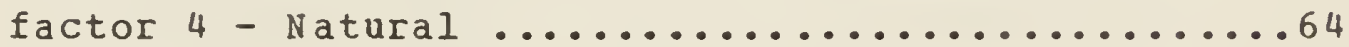

Takle 25 - Analysis of covariance on factors:

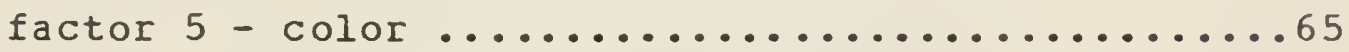

Table 26 - Manova: error sum of squares and cross

products matrix ....................... 66

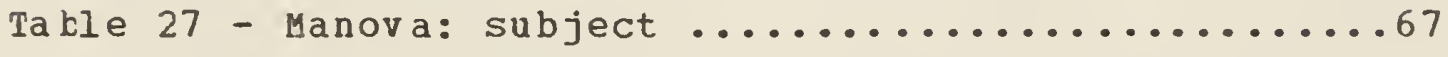

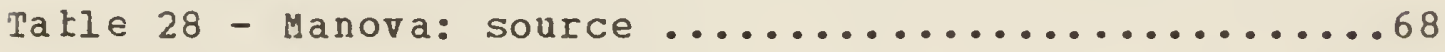

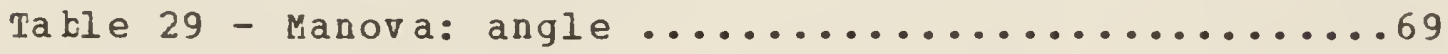

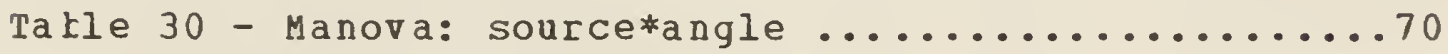




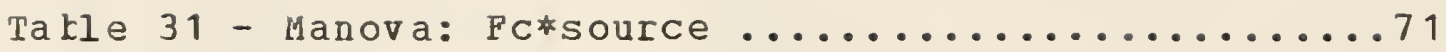

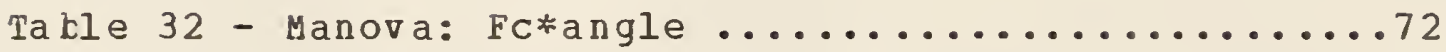

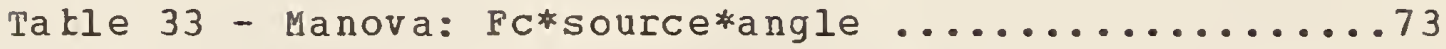

Tatle 34 - Correlation coefficients and their

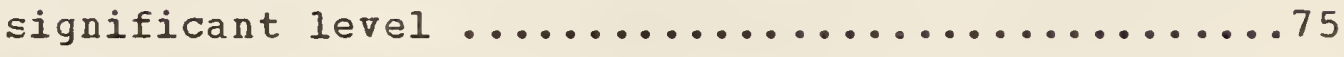

Tatle 35 - Factor means by condition and source .....84 


\section{INTRODUCTION}

The relationship between light and visual performance has been studied for a long time. The Hawthorne study. conducted in the 1920's by Western Electric is well known amcng the early ones (Parsons, 1974). New developments such as fluorescent lights, helped satisfying the growing demand for light. Electricity was cheaply produced and widely used. Daylight acceeded to artificial illumination as the number of tasks requiring increased accuracy became more and more common in industry. Execution of most of these tasks reguires a high degree of visual acuity. In the last 20 years, daylight has been almost forgotten as a source of illumination. The accelerated depletion of fossil fuels and rising prices of electricity called for energy conservation: it $l \in d$ to even greater reduction of fenestration, considered as a source of undesirable heat gains or losses. This conceft is now being revised as misleading.

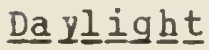

raylight was for ages the main and best light available in buildings for visual tasks. Electricity made posible incandescent lamps that were used mainly as a supplement. The afpearance of fluorescent lights coincided with other trends such as the advent of building air conditioning systems and low cost electricity. These facts combined to eliminate daylight as an essential element in building design. As a result, there has been little serious interest 
in daylighting in the United states in the last twenty years. Lighting accounts for about 20 percent of total electrical energy consumption in the United States. The en $\in$ gy crisis, consequence of disappearing natural resources and increasing energy prices drew attention back to daylight as a possible source for savings.

The recommended practice of daylighting, report of the IES committee(1962) had been the basic standard. Other putlications, such as Daylighting (Hopkinson, Petherbridge and Longmore, 1966) and Libbey-Owens-Ford (1976) give detailed techniques of daylighting design. This standard has been revised and updated into the new recommended practice of daylighting(1979); this report included a review of visual performance criteria, daylight as a source, daylight design principles, and methods for designing for daylight. There are some physical advantages in daylighting to consider. There is ample daylight to make its use in the lighting of building interiors definitely feasible. The direct illumination from a side window wall strikes the typical desk top at a relatively large angle of incidence, a desirable situation for improving the visual task by reducing the loss of contrast from veiling reflections. veiling reflections occur when light from a kright source is reflected upon the glossy parts of the task onto the observer eyes, decreasing contrast. The horizontal nature of window light also helps to define surface textures and to imfrove the modeling of objects within the interior. 
Further, daylight, through its variable nature, creates a highly dynamic character within the internal environment of a room. Daylight has a continuous wavelength distribution regarded as better than the discrete spectral distribution of fluorescent lights. In addition, the incidence of solar energy on the building provides heat that can substantially reduce the building's use of energy in winter.

The effect of glare and veiling reflections was studied by Griffith(1964), using scale model rooms. Contrast values we re computed for five tasks viewed at three different viewing angles. The tasks included type, pencil, ink, ballpoint pen and print. He reported a considerable loss of contrast for overhead systems as compared to sidewall window lighting. Lewin and Griffith(1972) used the contrast rendition factor and the equivalent sphere illumination concepts to compare the efficiency of sidelighting with conventional overhead systems. Sidelighting produced better results.

Some misconceptions developed with the energy crisis: first, the thought that conservation is not using energy: second, that reducing window area reduces energy consumption. The advantages of daylight footcandles from windows could provide enough energy and prove economical with a different approach to building design. The kuilding shculd be designed to operate as a total system instead of independent subsystems (lighting, air conditioning, etc). A careful economic evaluation over the entire life of the 
building, using techniques such as life-cycle cost-benefit analysis is also needed. This resource optimization was examined by Griffith $(1975 ; 1978)$, and recommended by the IES daylighting committee(1979). New developments such as prismatic glass blocks, glass coatings and photo-controls (Selkowitz, $1979 a$; 1979b) provide means for more effective utilization of daylighting.

Daylight alone is not enough to provide high levels of illumination. It should be supplemented by artificial lighting. The Permanent supplementary Artificial lighting in Interiors (PSALI) concept was to develop an integrated lighting technique which would retain the best features of lighting through windows and of well designed artificial lighting. The technique was developed in the 1950's and is fully described by Hopkinson and Collins (1969, Chap. 11).

What has been said about daylight, so far, refers to objective, functional aspects. Issues on lighting are, in many cases, highly subjective. A survey of the literature on psychological reaction to environments with asd without windows, by Collins(1975), indicated inconclusive results. "Although the conclusion that windowless rooms are not particularly desirable appears legitimate, this opinion is not based upon a large number of investigations. In fact, the best evidence for this dislike comes from one study of windowless offices and one of windowless intensive care units"(Collins, 1975, p.77). The intensive care unit study was conducted in two general hospitals in El Dorado, 
Arkansas by Wilson(1972). The hospitals served the same community, had comparable nursing staff and were attended by the same physicians. One intensive care unit had windows, the other did not. Wilson studied 50 patients in each unit that had undergone major surgery. hie found that more than twice as many patients in the windowless intensive care unit develcped post-operative delirium. (1) The reactions toward windowless environments varied from dissatisfaction to acceptance. Dissatisfaction occured in offices while windowless department stores were normally accepted. The investigations into reaction to windows suggested some of the renefits, but did not provide any answers about why windows are desirable.

cn the other hand, research conducted on physiological effects indicated that "environmental lighting exerts imfortant effects upon human health and productivity, far beyond its requirements for vision"(Wurtman, 1973, p. 79). Di rect effects of light on cells on or near the surface of the body include erythema (sunburn), tanning and (very rarely) an increase in the incidence of skin cancer. There are also direct effects of light on vitamin D, on bilirubin and on drugs which act as photosensitizers. It is known that the body can synthesize vitamin $\mathrm{L}$ up to a critical point. The vitamin D precursor is transported to the skin,

(1) This syndrome can be defined "as an acute brain sy ndrcme characterized by impairment of orientation, memory, intellectual function and judgement with lability of áffect." (Morse and Litin, 1969) 
where it is activated by light, and then carried back to the liver and kidneys for additional enzimatic changes. Bilirubin is a breakdown product of the hemoglobin released when red blood cells die. Its accumulation causes the skin to become yellow or jaundiced. An English nurse observed that newborn infants whose cribs were near open windows develcped jaundice less often than infants whose cribs were at a distance from windows. This led to the discovery that light exposure could accelerate the rate at which bilirubin could be excreted or destroyed. A certain number of widely us $\mathbb{d}$ medicines are activated by light, yielding intermediates which can damage tissues. These compounds are phctosensitizers. "It should be obvious that if environmental light affects three or four known compounds, it is just as likely to affect a much larger number of still un known compounds." (พurtman, 1973, p80)

There are also indirect effects of light on sexual maturation. It was shown that girls blind from birth had a significant acceleration of sexual maturation. The pineal gland is also affected. It responds to rervous signals by releasing more or less of its hormone, melatonin; the rate at which melatonin is synthesized seems to depend upon envircnmental lighting. Biological rhythms are also indirectly affected by light; the rhythm of body temperature was cited as one of them (Wurtman,1967, 1968). Studies on animals and men (Hollwich, Dieckhues and Meiviers, 1975) led to ccnclusions of some damaging effects on the eye by 
artificial light. The cause most often mentioned, among others, was the difference in spectral distribution of artificial lights from daylight.

A pilot study conducted by the author at kansas state University did not reveal any difference in performance between fluorescent light and daylight. In this experiment 20 surjects (ten males and ten females) inspected sets of Landolt rings under either one of the two sources, at two different illumination levels. Ferformance was first measured under daylight and yoked control used for the fluorescent.

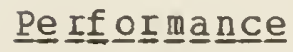

Considerable attention was paid to the subject of illumination by H.C.Weston(1949). His work set the pattern for future research and the basis for lighting codes. In his experiment, a sheet of paper with 256 Landolt rings printed on it was used. The gap in each ring subtended the desired visual angle and was oriented in any of eight positions. The subject inspected the rings and marked those having a particular orientation. Ferformance was obtained by multiplying the inverse of the time required to perform the visual task, by accuracy. Accuracy was simply the proportion of rings correctly identified. The results shcwed a series of curves with performance increasing as illumination is raised.

One of the shortcomings of weston's experiments was his 
definition of performance, as explained by Blackwell(1952). Increases in performance represent increments in either speed or accuracy or both, in indeterminate amounts. The experiment conducted by Blackwell(1952) consisted of the prcjection of a circular target on a translucent screen for fixed amounts of time. Subjects were to identify the time interval, in a sequence of four, in which the target appeared. During the course of his experiment, the field luminance, target diameter, and exposure duration were all varied. The basic data recorded were the number of times each observer correctly identified the interval occupied by the target for a given set of conditions. He concluded that the ability to distinguish contrast increases with luminance. The data so obtained were later used by Blackwell(1959) to develop a method for specification of illumination levels. His data, of the threshold type, required some sort of translation to be used to specify illumination for tasks of various difficulty. This translation takes the form of several steps; the most important, is the multiplication by a field factor, obtained from his experiment with the "Field Task Simulator". To validate the use of his data, Blackwell designed an apparatus called the "visual Task Evaluator", the principle of which is to reduce the visibility of an actual task by reducing its contrast by a known amount. The validity of the method rests on the assumption that tasks equivalent at threshold visibility are also equivalent at suprathreshold 
le vels.

A correlation between the Blackwell and Weston work was done by Fry (1962). In the task created by Fry, Landolt rings were presented intermittently and the subject reguired to indicate the direction in which he believed a gap to be oriented. The rate and duration of exposure were controlled by an automatic timing device. Data were obtained at threshold and suprathreshold levels. Performance curves at sufrathreshold were parallel to the threshold curve; they we Ie in agreement with Blackwell's threshold and Weston's sufrathreshold data. Purther studies in the same direction conducted by Boynton and Boss(1971), and Blackwell and Scct(1973) confirmed the theory that more light means better performance.

The definite factor determining visual performance is not inherent to the task. It is the buman subject. The entire process may be considered a three step activity: seeing, thinking, and responding. Some research done on hulian performance has been strongly dependent on response Iimitation; Weston's is a typical example. Response liritation occurs when extended mental processing and motor response overbalance visual aspects of the task. other factors, such as motivation, stress, fatigue, etc. play important roles in human performance and must be taken into account. One study by McNelis(1973) tried to account for most of these factors. The task selected involved viewing twc displays of single lower case letters which were 
se parated by ten degrees, and verbally reporting what was seen. Accuracy was scored. The ten degree separation assured that both displays could not be fixated simultaneously. An exposure time of 0.4 second was adopted. By changes in contrast and illumination, basic performance relationships were determined. Functional relationships between contrast, background luminance, and accuracy for either left or right letter, and both were obtajned. The ey€ mcvement patterns were also identified.

Although visual performance increased with illumination, there was an illumination level above which it was expected to decrease sharply. In an experiment conducted by Smith(1978) a series of office tasks were compared under different illumination levels. The results shcwed a function relating illumination and performance that incresed monotonically and flattened at high levels. Performance for the tasks compared did not deteriorate even at levels up to 409 footlamberts.

It must be recognized that there are many factors affecting performance of visual tasks besides illumination levels. Primary factors influencing visual tasks are size, time, background brightness and contrast. Size and time are variakles long studied. Hopkinson and Longmore(1970) reforted on the effects of different backgrounds on attention and performance. The importance of contrast has been shown by papers already reviewed. However, in most of the experiments the task was presented in a two dimensional 
form; it was also shown under special illumination systems. In actual practice in industry, most of the visual tasks that are considered difficult are not two dimensional. The presence of three dimensional characteristics in a visual task greatly expands the opportunities for effective manifulation of light falling upon the task. This dimensional aspect of task is of great importance when considering veiling reflections, and sometimes glare, and their effect of contrast reduction. Faulkner and du rphy (1973) showed the improvements achievable with special purpose lighting in many situations, and how general illumination and high levels might be undesirable. Lewin and Griffith(1970) used the same concept of directionality in the design of the twin beam luminaire. Fever footcandes were used more efficiently since veiling reflections are prevented.

Application of the relationships developed is difficult, though. In a survey of offices by Henderson, MCNelis and Williams(1975), the most comon important tasks were identified and their visibility levels measured. The wide variety of tasks and visibility levels found had different illumination requirements. They recommended consolidation of work of similar difficulty and the use of non uniform lighting.

A different approach to researching light-performance relationships is using practical tasks. These tasks involved complex stimulus objects and materials, having 
selected realistic characteristics. They have the three performance components (visual information aquisition, mental processing, and motor response) incorporated, the visual step being the most important. This type of experiment was used by Lion, Richarason and Browne(1973) to compare inspection performance under fluorescent and tungsten (incandescent) light. Some specific tasks have been developed to study variables affecting light performance relationships. The needle probe task used by Smith(1976) yielded compatible results with those reported by other investigators. Other tasks have been developed and used by Smith and Rea(1978) and Bennett, Chitlangia and Pangrekar (1977).

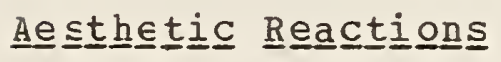

It has been already stated that the amount of illumination is not the only variable influencing visual performance. At least two studies have been previously menticned relating other characteristics, such as directionality. The information content and meaning associated with visual stimuli are linked to light modes. As these lighting patterns are modified, the composition and relative strength of visual signals and cues are changed. These in turn alter the impressions of the user. The Illuminating Engineering Research Institute supported research exploring this lighting cue theory, or subjective effects of environmental lighting.

A methodology was 
developed (Flynn, Hendrick, Spencer and Martyniuk, 1979) and soue interim reports published (Flynn, et al, 1973). This "semantic differential" technique is based on rating scales, such as "clear-hazy", "bright-dim". Work with such scales has identified several broad categories of impression that can apparently be modified by lighting systems. The recommended procedures fell into two stages: data collection, and data analysis. The data collection included: selection of stimulus conditions, selection of bicolar rating scales, and design of the experiment. The data analysis included scoring and techniques for the statistical analysis of the data.

The multidimensional scaling procedure asks for overall judgements of similarity or difference, and the subject is left to establish his own criteria, as opposed to the semantic differential procedure.

These procedures have been used to evaluate different envircnments. Flynn, et al (1973) studied different light arrangements for a conference room type setting. Flynn and Spencer (1977) were primarily interested in the comparative responses to several typical light source colors, in the range 2100 to $4200 \mathrm{~K}$. Color temperature is measured in degrees Kelvin and is based on the black body concept: the spectrum of wavelengths emitted by an incandescent light source changes with temperature. The approach taken by Bennett, Ali, Perecherla and Rubison(1978) used scale model rocms; they examined sources, level, and arrangements on 
rocm type (living or waiting room). Hawkes, Loe and Rowlands (1979) tested arrays of luminaires for preference and energy consumption, in an office-like setting.

One of the impression categories identified using the semantic differential technique was "visual clarity". This concept deserves a closer examination. A theory of visual clarity has been provided by Thornton and chen (1978). It considered the eye as a light detector with a particular spectral distribution. A signal of certain energy content at a given wavelength would produce an output response that is a fraction of the response at the sensitivity peak of the detector. Three sensitivity peaks were defined for human beings, at wavelengths corresponding to the prime colors. The experiment behind the theory involved succesive couparisons of two furnished enclosures (one was mirror image of the other) for four types of lamps. Illumination on one side was dimmed to produce equivalent visual clarity. The authors concluded that illuminants concentrating their power at those three prime color wavelengths yielded superior visual clarity of the illuminated scene. In an exferiment by Lemons and Robinson(1976) subjects observed black-and-white as well as colored objects placed in two adjacent boxes. Fourteen lamps were tested. The illumination level of the scene was changed using an adjustable baffle. Relationships of visual clarity to color temperature, CRI (Color rendering index) and illumination were observed. Less illumination was required as CRI 
increased to provide equal visual clarity; warmer light sources seemed to improve visual clarity. The explanation was based on Kruithoff's principle as is shown in Figure 1: visual clarity corresponds to the acceptable zone of the graph. A strong criticism to the visual clarity concept came from Delaney, Hughes, McNelis, Sarver and Soules (1978) who using semantic differential technique concluded that visual clarity is not a concept distinguishable from others as brightness or colorfulness. The issue is still un decided. 


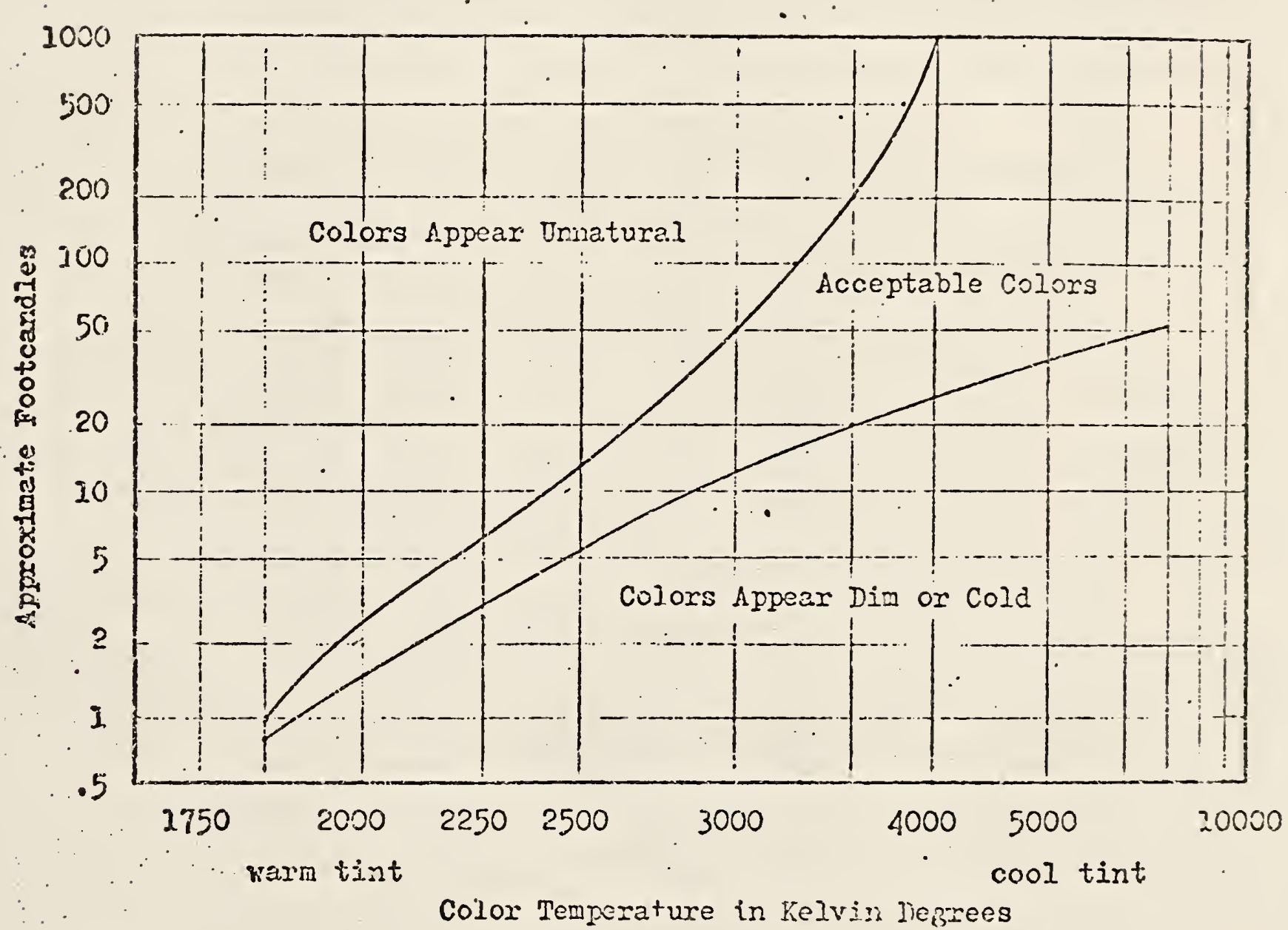

Nigure 1

Krufthoff's principle - Relationship of color temperature to luminance Ievels 
PROBLEM

The purpose of this research is to evaluate daylight as a source. It will be compared with cool white fluorescent, the mcst common fluorescent source in use in North America. Griffith (1964) demonstrated that daylight coming from the side provided greater contrast than standard overhead systems, thus, the directional effect will be considered for both sources.

Fast research on illumination requirements involved abstract visual tasks; this research will use practical visual tasks, similar to those found in real life situations.

Performance will be objectively measured by the time to perform; further, by a subjective evaluation of dificulty.

Flynn, et al (1973, 1979) and other investigators have identified several categories of impression associated with lighting systems. The lighting conditions will be evaluated using the semantic differential technique.

specific hypothesis of this research are:

1. Performance is better under daylight than under fluorescent light.

2. Performance is better when light comes from the side than under toplighting.

3. Evaluation of user impressions, categorized (clarity, spaciousness, evaluation), favors daylight.

4. Sidelighting is preferred to toplighting. 
METHOD

Iwo approaches were taken. First, three different tasks, needle probing, proofreading and graph reading, were used as practical tasks. These tasks were modifications of some used before in other research (Smith, 1976, 1978; Chitlangia, 1976). The second approach made use of semantic differential rating scales to record subjects' impressions. The same 30 subjects supplied the needed data for the two parts of the study; both sets of data were obtained in the same individual session. Two sources, daylight and cool white fluorescent, were used, at different levels, and from two different directions: top and left side.

\section{$\underline{T} \underline{\underline{a}} \underline{\underline{k}} \underline{\underline{S}}$}

The tasks selected involved visual discrimination at suprathreshold levels and were selected for their high visual content, therefore minimizing response limitation. These were considered to be practical tasks that people come across similar in real life situations; for example, succesful probing is necessary for sewing on a button, needlepoint sewing, spot soldering, and countless assembly tasks. Written instructions were given to the subjects. These instructions are shown in Figure 2.

Neᅳed 1) were mounted on a wooden block, such that the needles faced the subject. The task was to place a thin piece of wire through the needles. 


\section{INSTRUCTIONS and INFORMED CONSENT}

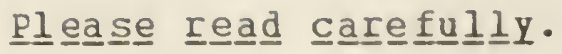

This experiment is designed to measure the effect of illumination on work performance. You will be asked to do three different tasks: needle probing, proofreading and graph reading, under four different illumination conditions. specific instructions will be provided expiaining the prccedures for performing each task. It is important that you understand the procedures, therefore, some trials before the experiment will be given to get you acquainted with them. Time will be recorded as a measure of your performance.

After every task you will have to rate the performance of the task under that level of illumination. The rating shculd be according the scale posted in front of you. Please do not rate on the basis of how quickly you performed, but on the basis of how easy or difficult that task was to see and perform under that illumination.

Further, you will be asked for a subjective evaluation of the quality of illumination. Some bipolar scales will be provided, with the characteristics to analyze, listed. Please judge illumination under these quality characteristics.

The approximate time to complete the experiment will be

\section{FIGURE 2}

Instructions given to the subjects. 
60 minutes. There is no risk or discomfort involved. However, you are free to stop your participation at any time. Naturally I would prefer you to continue until the end so that I can obtain all of the needed data. If you have any questions, now or later, feel free to ask.

Figure 2 (cont.)

Instructions given to the subjects. 


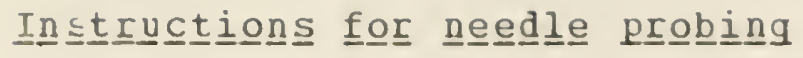

A wooden block, on which five needles are mounted, will te placed in front of you. The eye of all five needies will te facing you. You will be provided with a thin wire to be used for probing. Keeping the wire in your preferred hand, first probe the wire through the needle marked No. 1 , then through the marked No. 2, and so on, until you have prcbed them all.

Iry to perform this task with the maximum speed you can; tiue will be the measure of performance. Remember that while probing the needles, you are required to probe the full length of the wire through every needle.

Figure 2 (cont.)

Instructions given to the subjects. 


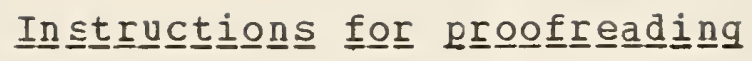

you are going to proofread a paragraph, looking for misspelled words. When you find one, mark the word with a slash. There are 20 misspelled words in each paragraph; you are supposed to identify at least 18 of them in the shortest tiue possible. The misspellgs are selected in on the basis of visual similarity and are given in the following rable.

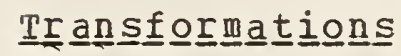
$\mathrm{n}$ for $\mathrm{h}$
$h$ for $n$
1 for $i$
i for 1
$f$ for $t$
$t$ for $f$
o for C
C for o

Figure 2 (cont.)

Instructions given to the subjects. 


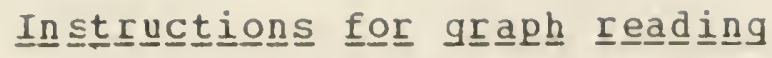

you will be given a sheet containing a set of curves. A card containing three number-letter pairs will be shown to you. Look at the first pair. Locate the first number on the vertical axis, move horizontally until the curve marked with the letter and then down to the horizontal axis. Read the number on the axis aloud, so I can hear you, giving three digits after the decimal point. You should be 100 per cent sure of your answer. Repeat the process with the other two pairs.

Figure 2 (cont.)

Instructions given to the subjects. 


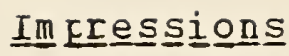

you are now going to rate the quality of the light used. Please rate on the basis of the scales given only. A sheet containing several scales with key words on both ends will be used. Place an "y" in the position in the scale that rest describes your impression. An example of the scale values is given using the key words "good-bad".

Neither

Very Moderately slightly Good nor Slightly Moderately Very Go cd : g으으 : - goood : goood : $\underline{\text { ba d }}$ : baa․ : $-\underline{b a} \underline{a}$ : ba $_{\text {a }}:$ : Ba

Each rating should be made in similar fashion. Be sure to read both words at each end of the scale before you decide where to make the "X". There are no right or wrong answers to this task. We want your subjective judgement concerning how the light appears to you.

Figure 2 (cont.)

Instructions given to the subjects. 
TAELE 1

Needle numbers and dimensions of needle eye.

\begin{tabular}{|c|c|c|}
\hline Neᅳedㅣㄹㅡ & $\underline{\text { Le}} \underline{\mathrm{n}} \mathrm{g} \underline{\mathrm{t}} \underline{\mathrm{h}}$ & Wid $\underline{\underline{t}} \underline{h}$ \\
\hline$\underline{n} \underline{\mathrm{u}} \mathrm{m}$ be$\underline{\underline{I}}$ & (므묘) & (므므) \\
\hline 1 & 0.031 & 0.122 \\
\hline 2 & 0.036 & 0.130 \\
\hline 3 & 0.036 & 0.208 \\
\hline 4 & 0.057 & 0.33 \\
\hline 5 & 0.073 & 0.749 \\
\hline
\end{tabular}


The wooden block was placed in front of the subject. The subject was asked to hold the thin piece of wire in his preferred hand. Subjects were required to probe the full length of wire ( 5 cms.) through all needles, starting with the needle marked number 1 and going on until the needle marked number 5. The procedure was repeated two more times. Sukjects were requested to perform as quickly as they could.

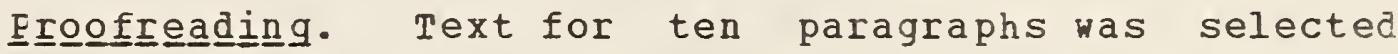
frcm the Bible. Paragraphs were 95 to 105 words long, refroduced on white paper, and in columns three inches wide. Each paragraph contained 20 errors, random distributed; no word contained more than one error. Errors were replaced letters, selected on the basis o£ visual similarity. Figure 3 shows the table of letter transformations. subjects were instructed to indicate errors by making a slash mark through each word containing an error, to minimize response time. Number of errors and letter transformations were explained to subjects; preliminary trials acquainted them with the system. Time wa $\leqq$ recorded.

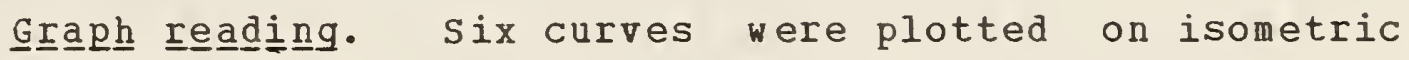
pafer. Reproductions made on white bond paper were used in the experiment. Subjects were instructed to read the graph in a given manner, to a specific accuracy. Time was recorded as a measure of performance. The graph is reproduced in Figure 4. This experiment was also repeated three times under each lighting condition. 


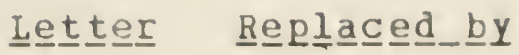

$\begin{array}{ll}\text { n } & \text { h } \\ \text { h } & \text { n } \\ \text { l } & \text { i } \\ \text { i } & \text { l } \\ \text { f } & \text { t } \\ \text { t } & \text { f } \\ & \\ \text { o } & \text { c } \\ \text { c } & \text { o }\end{array}$

Figure 3

Letter transformations 


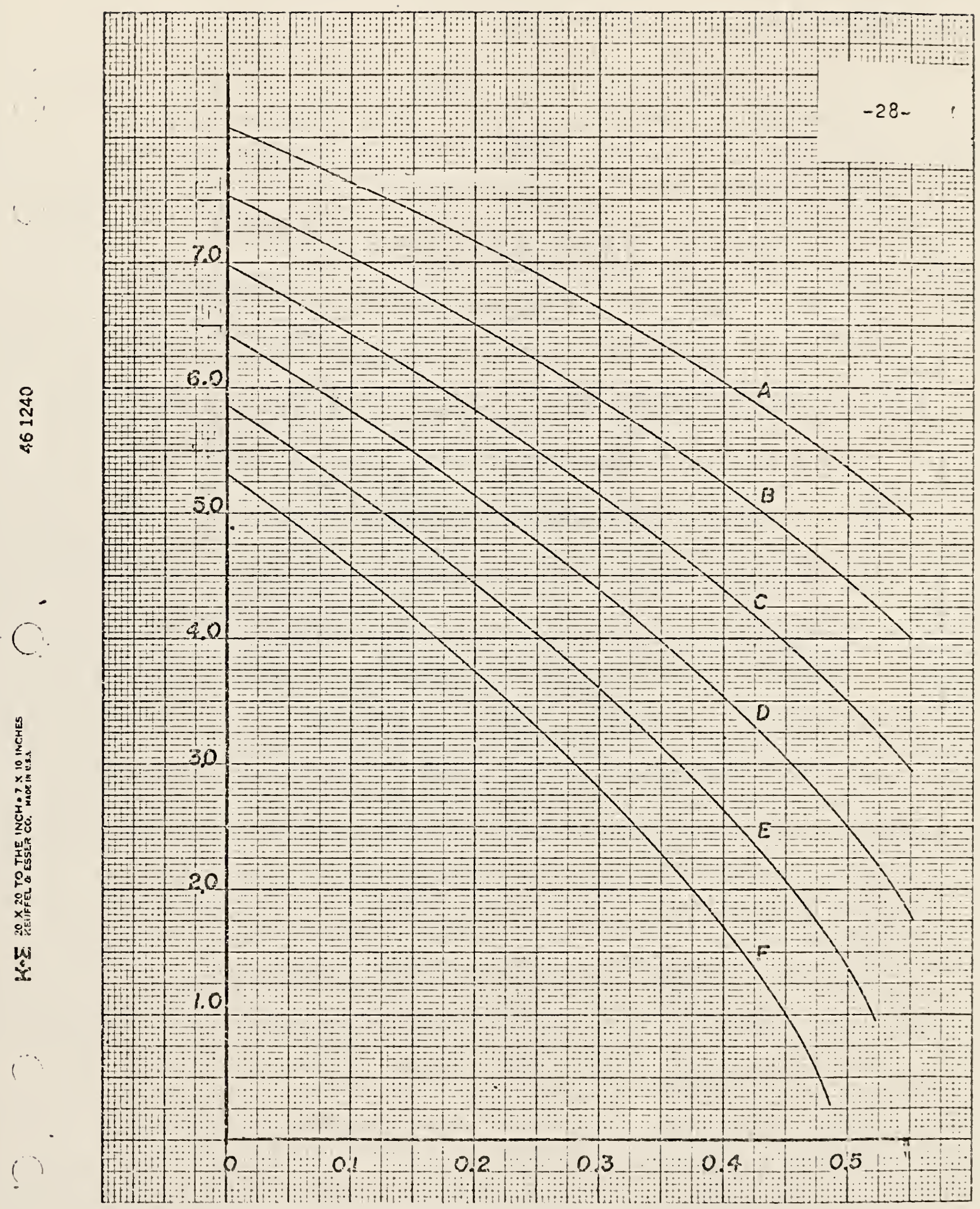

Figure 4

Graph used in the graph reading task 
Time to complete each task was recorded by means of a stcpwatch, in thousanths of a minute.

Also, after completion of every task, subjects were asked to rate each condition on the basis of how easy or difficult that task was to see and perform under that level of il lumination.

The ratings by the subjects were based on Borg Relative Perceived Effort Scale (Borg, 1962, cited by Gamberale, 1972):

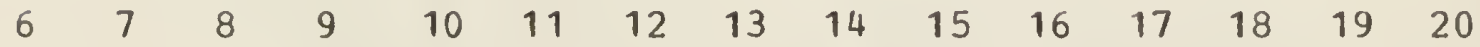

\begin{tabular}{|c|c|c|c|c|c|c|}
\hline Very & Very & Easy & Some & Hard & very & Very \\
\hline Very & Easy & & What & & Hard & Very \\
\hline Easy & & & Hard & & & Hard \\
\hline
\end{tabular}

In physical tasks the ratings correspond closely to heart rates (times ten). In non-physical tasks such as these, the ratings are simply indicators of difficulty.

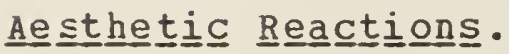

When each subject finished the tasks under a given condition, he was asked his impressions using semantic differential scales. The items were selected to fit this particular study, from scales mentioned in the literature (Flynn, et al, 1979; Thornton and Chen, 1978; others). There were two scales for each one of the most commonly recognized categories: visual clarity, spaciousness, evaluation. Four more scales were included to detect what have been called "modifying influences". Clarity was 
refresented by the clear-hazy and bright-dim scales, spaciousness by large-small and wide-narrow, evaluation by like-dislike and pleasant-unpleasant, and the modifying influences by the warm-cool, glare-nonglare, colorfulcolorless and natural-unnatural scales. The order of presentation of the scales was randomized. Figure 5 presents a sample form containing the rating scales.

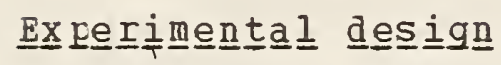

Two light sources, daylight and cool white fluorescent (CWF) were used in the experiment. They were provided from twc different directions: top and left side.

The setup was done in a room 2.40 meters long by 2.40 meters wide, and it is pictured in Figure 6. Daylight came through a window in the north wall; the fluorescent fixture having four 40 watt CHF tubes was placed parallel to it. The two sources were side by side and each covered with a 60 by $120 \mathrm{~cm}$ plastic luminaire lens. The rest of the wall was covered with plywood paneling. Outside of the window was a rocf covered with black tar. A transformer on the line of the fluorescent fixture allowed diming of the light.

The experiment was carried out in a lighting booth, as sketched in Figure 7. The chamber was $60 \mathrm{~cm}$ wide, $60 \mathrm{~cm}$ high and $50 \mathrm{~cm}$ deep, flat white color in the inside. The height of the booth was $100 \mathrm{~cm}$; a specular surface was used as reflector and roof of the booth. The left side was open on the upper part but had a difuser lens in the lower; 
SUBJECT:

CONDITION:

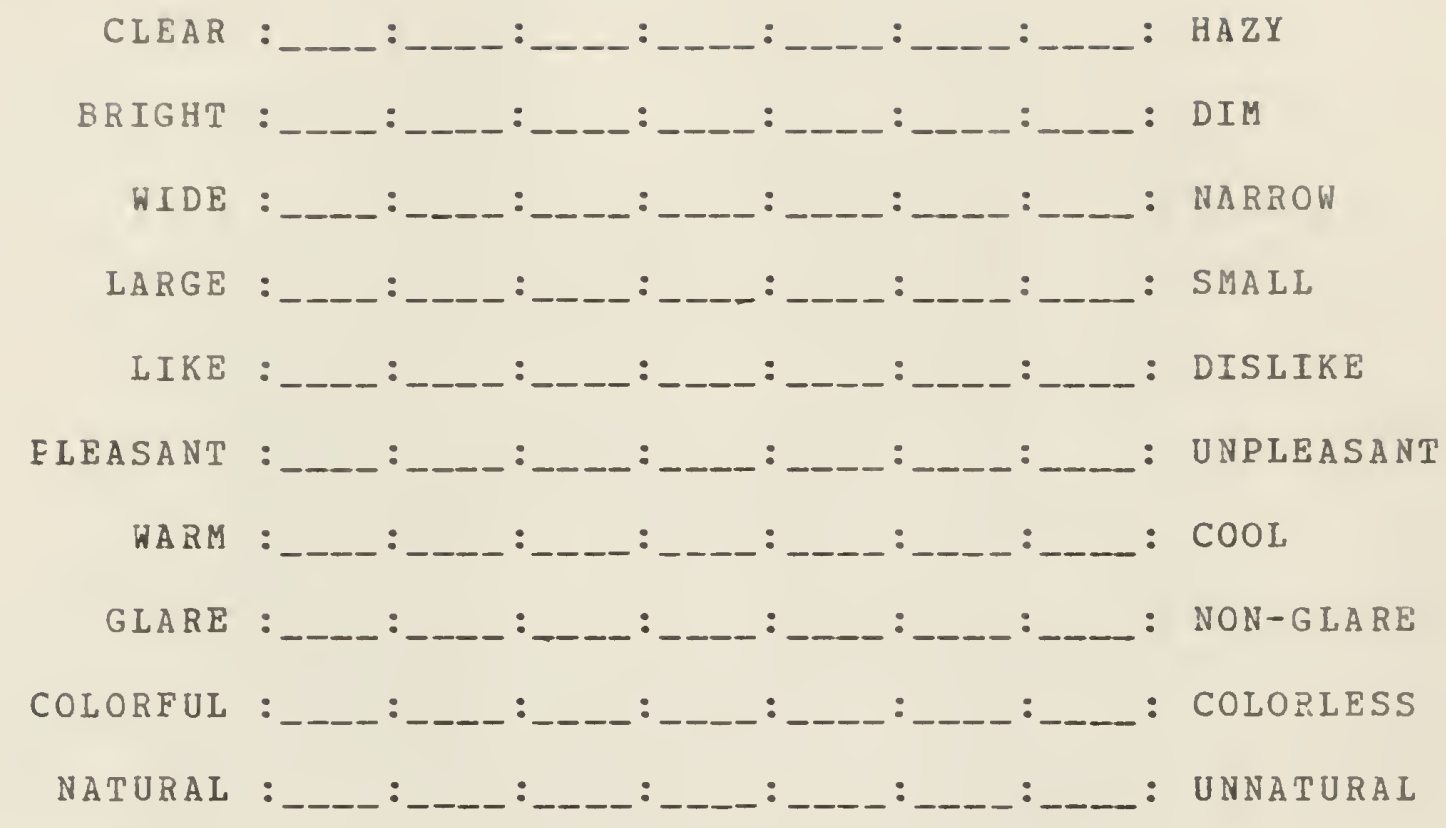

Figure 5

Sampling form containing the rating scales. 

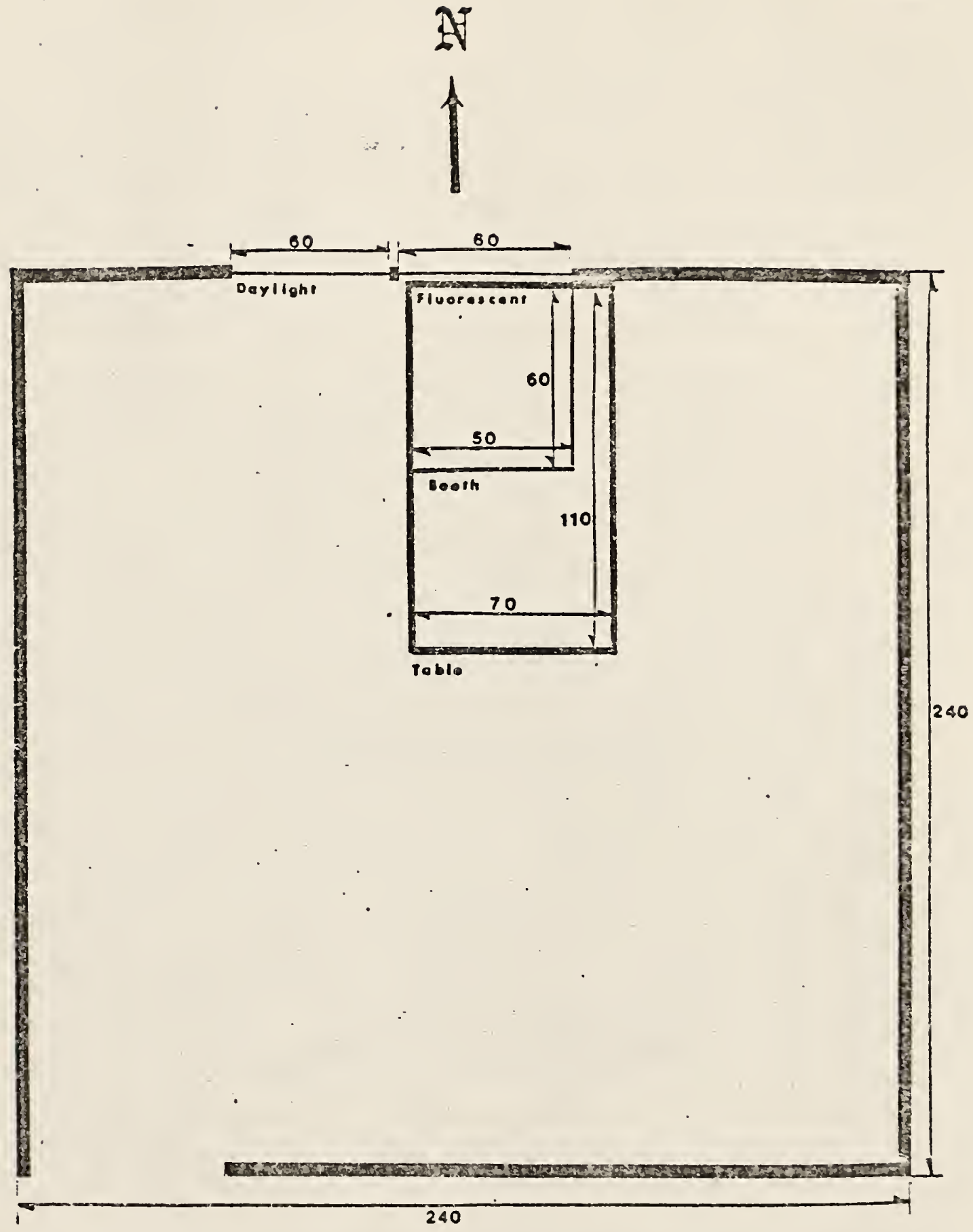

Figure 6

Plan of the seting. Dimenstons in centimeters. 


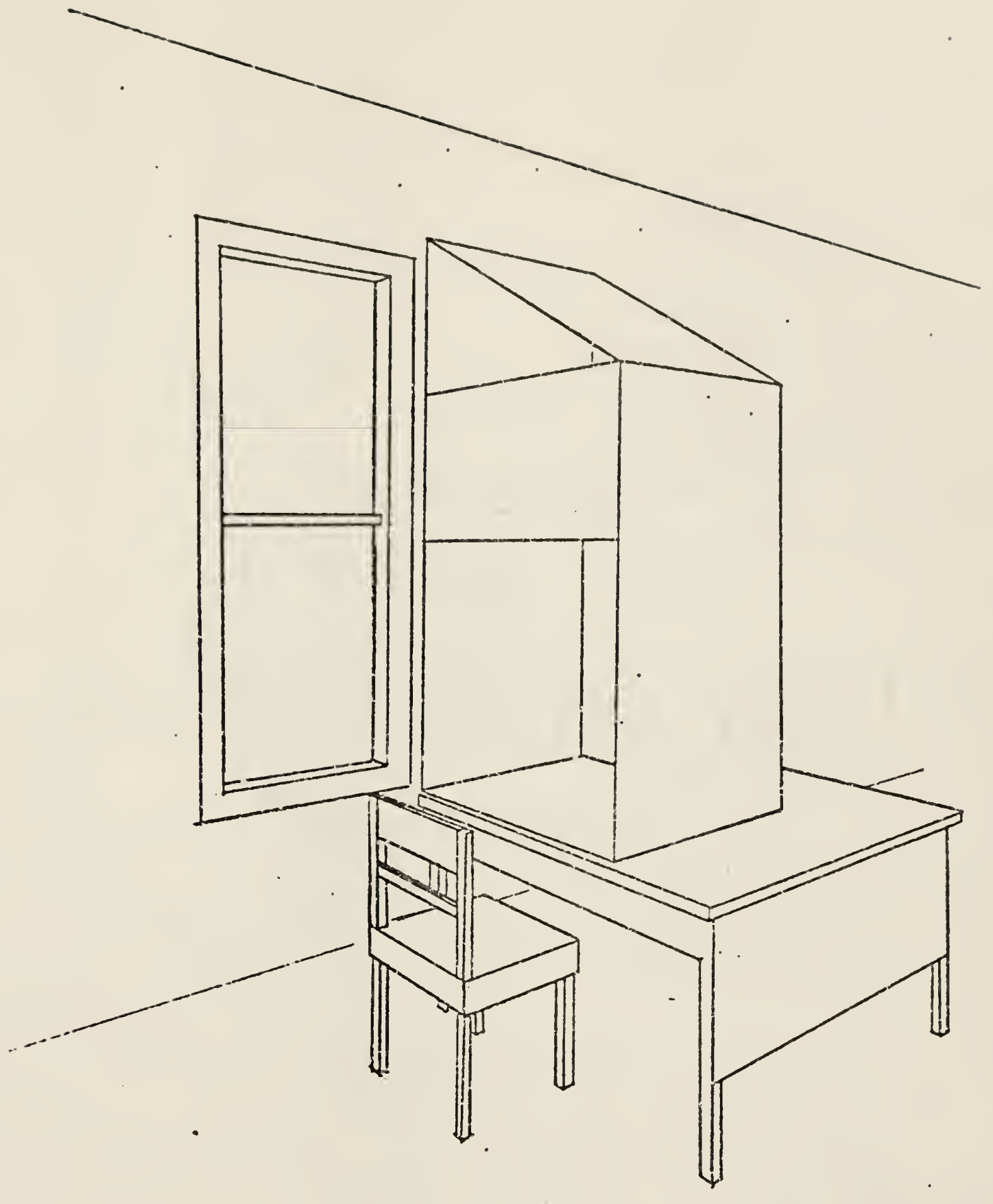

F⿻ grise 7

Vlew of the set-up with the booth 
this was to provide equal levels of illumination. A piece of white mat board was used as the roof or left side for the chamber as the conditions required. The booth was placed on top of a table such that the working surface was $75 \mathrm{~cm}$ above the floor. An adjustable chair was used by the sutjects.

The illumination level was measured under daylight, and the fluorescent light was adjusted accordingly. one of the sources was then covered and the subject tested; sources we re then reversed and the tests run again. The booth was placed against the wall. Differences among illumination for the four conditions were kept within 5 per cent. Illumination levels were monitorea by means of a light meter. No subject was run at less than 30 footcandles; they were run after 8:30 a.m. and before 5:00 p.m. Irom March 10 to March $21,1979$.

The two sources, two illumination angles and three tasks were taken as the independent variables. Heasured as de fendent variables were time to perform and the ratings given by the subjects.

subjects were randomly selected; source order was randomly assigned to subjects. Angles and tasks were then randomized for a given source.

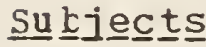

Thirty subjects, eighteen male and twelve female served in this experiment. All of them were students at kansas 
State University, enrolled in different colleges and at diverse levels. The age of the subjects varied trom 18 years to 29 years with a mean of 22.6 years. Their bi cgraphical data is listed in Table 2 . 
TAELE 2

Bicgraphical data of the subjects.

\begin{tabular}{|c|c|c|c|c|c|}
\hline Sukject & $\underline{\underline{S}} \underline{\underline{e x}} \underline{\underline{E}}$ & (ㅍge & 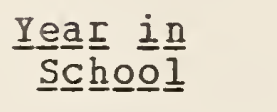 & 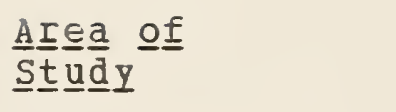 & 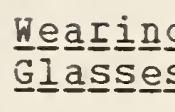 \\
\hline 1 & M & 24 & Sophomore & Vet Med & No \\
\hline 2 & $M$ & 28 & Graduate & Physics & Yes \\
\hline 3 & $\mathbf{F}$ & 23 & Graduate & Food Science & No \\
\hline 4 & $M$ & 22 & Senior & Ind Eng & Yes \\
\hline 5 & M & 26 & Graduate & Ind Eng & Yes \\
\hline 6 & F & 21 & Senior & Ind Eng & No \\
\hline 7 & M & 27 & Graduate & Journalism & No \\
\hline 8 & $M$ & 24 & Senior & Animal Science & No \\
\hline 9 & M & 23 & Graduate & Plant Pathology & Yes \\
\hline 10 & $\mathbf{F}$ & 27 & Graduate & Sp Education & No \\
\hline 11 & M & 29 & Graduate & Enthomology & No \\
\hline 12 & M & 18 & Sophomore & Electrical Eng & Yes \\
\hline 13 & $\mathrm{~F}$ & 20 & JunioI & Microbiology & No \\
\hline 14 & $\mathrm{~F}$ & 22 & Graduate & HPER & Yes \\
\hline 15 & M & 23 & Graduate & Ind Eng & Yes \\
\hline 16 & $\mathbf{F}$ & 28 & Graduate & Grain Science & No \\
\hline 17 & M & 20 & Sophomore & Ag Eng & Yes \\
\hline 18 & $\mathrm{~F}$ & 19 & Freshman & Psychology & Yes \\
\hline 19 & $F$ & 22 & Senior & Food science & No \\
\hline 20 & M & 21 & Junior & Landscape Arch & No \\
\hline 21 & M & 20 & Junior & Accounting & No \\
\hline 22 & $F$ & 20 & Junior & Horticulture & Yes \\
\hline 23 & M & 20 & Junior & Mech Eng & Yes \\
\hline 24 & F & 22 & Senior & Home EC & No \\
\hline 25 & 11 & 23 & Graduate & Psychology & Yes \\
\hline 26 & F & 20 & Junior & Bus Admin & Yes \\
\hline 27 & M & 20 & Junior & Bus admin & Yes \\
\hline 28 & M & 22 & Senior & History & No \\
\hline 29 & $\mathrm{~F}$ & 25 & senior & Mech Eng & Yes \\
\hline 30 & M & 19 & Sophomore & Biology & No \\
\hline
\end{tabular}


RESULTS

Each subject performed a task several times under each condition. The time to perform was averaged and recorded as the performance. Tables 3,4 , and 5 present times to perform for the needle probing, graph reading and proofreading tasks respectively. The means follow the directional hypotheses: times are smaller for daylight and sidelighting for the three tasks. Figure 8 presents the mean times.

The level of illumination varied from subject to sukject, but it was constant for each individual. It was recorded and is presented in the second column of Tables 3,4 and 5. To measure the color temperature of the light source, a "Spectra" brightness spot meter (Photo Research Corp) was used. The ratio of the blue to red radiation is calculated, and the color temperature is obtained from a calikration curve. Since the calibration curve was not available for this instrument, the color temperature could not be calculated. The ratio appears in the tables as $B / R$, for each source. The ratio was calculated for daylight for each individual, but only once for fluorescent light. The results are plotted as a function of illumination (f cotcandles) in Figure 9. A complete separation of the two so urces is observable.

After completion of each task, subjects were asked how difficult the task was; the results are presented in Tables 6.7, and 8; the means in Figure 10. The scores are similar for the four conditions and no particular trend is observed. 
TAEL E 3

Needle probing: Time to perform, thousanths of a minute

\begin{tabular}{|c|c|c|c|c|c|c|c|}
\hline Su kjiect & $\underset{\text { Le }}{(\underline{\underline{f}} \underline{\underline{c}})}$ & $\underline{B} \angle \underline{R}$ & $=\frac{\mathrm{a}}{\mathrm{S}} \frac{\mathrm{i}}{\mathrm{i}} \mathrm{g} \underline{\mathrm{d}} \mathrm{h}$ & Top & \multicolumn{3}{|c|}{ 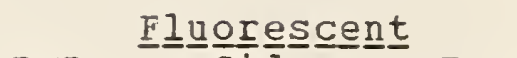 } \\
\hline 1 & 50 & 3.42 & 240.7 & 242.0 & 1.65 & 192.7 & 275.7 \\
\hline 2 & 40 & 4.67 & 314.7 & 339.7 & 1.69 & 323.0 & 269.7 \\
\hline 3 & 40 & 3.75 & 170.0 & 266.7 & 1.69 & 223.7 & 222.3 \\
\hline 4 & 30 & 5.73 & 208.7 & 197.7 & 1.67 & 196.3 & 204.7 \\
\hline 5 & 30 & 5.00 & 299.3 & 276.0 & 1.67 & 212.3 & 246.0 \\
\hline 6 & 32 & 4.90 & 138.3 & 173.3 & 1.65 & 234.0 & 231.7 \\
\hline 7 & 32 & 4.35 & 213.0 & 186.7 & 1.65 & 213.7 & 202.3 \\
\hline 8 & 32 & 4.84 & 262.0 & 191.0 & 1.65 & 267.3 & 247.3 \\
\hline 9 & 35 & 4.84 & 320.7 & 291.3 & 1.63 & 244.0 & 245.0 \\
\hline 10 & 40 & 4.71 & 138.3 & 197.0 & 1.69 & 179.0 & 184.3 \\
\hline 11 & 50 & 3.67 & 244.3 & 167.7 & 1.65 & 272.0 & 256.3 \\
\hline 12 & 65 & 3.33 & 203.7 & 282.3 & 1.69 & 350.3 & 254.0 \\
\hline 13 & 65 & 3.16 & 212.7 & 201.0 & 1.69 & 178.7 & 186.3 \\
\hline 14 & 40 & 3.30 & 203.7 & 197.3 & 1.69 & 231.7 & 188.7 \\
\hline 15 & 80 & 3.44 & 255.0 & 261.0 & 1.68 & 218.7 & 215.7 \\
\hline 16 & 40 & 4.29 & 256.7 & 261.0 & 1.69 & 243.0 & 266.0 \\
\hline 17 & 35 & 5.23 & 221.0 & 249.0 & 1.63 & 264.0 & 234.7 \\
\hline 18 & 35 & 2.63 & 251.0 & 295.7 & 1.63 & 254.7 & 215.0 \\
\hline 19 & 50 & 4.25 & 173.3 & 178.0 & 1.65 & 207.0 & 181.0 \\
\hline 20 & 50 & 3.88 & 174.7 & 197.0 & 1.65 & 123.0 & 126.0 \\
\hline 21 & 60 & 3.64 & 234.0 & 268.7 & 1.68 & 225.3 & 249.3 \\
\hline 22 & 50 & 3.57 & 210.0 & 201.7 & 1.65 & 264.0 & 349.0 \\
\hline 23 & 40 & 4.82 & 206.7 & 206.7 & 1.69 & 225.3 & 244.7 \\
\hline 24 & 40 & 4.62 & 250.3 & 233.7 & 1.69 & 226.0 & 224.7 \\
\hline 25 & 40 & 4.67 & 223.7 & 268.0 & 1.69 & 251.7 & 290.0 \\
\hline 26 & 35 & 4.57 & 276.3 & 350.0 & 1.63 & 290.7 & 358. \\
\hline 27 & 30 & 4.58 & 224.3 & 232.3 & 1.67 & 242.3 & 237.0 \\
\hline 28 & 50 & 3.63 & 283.0 & 207.7 & 1.65 & 273.7 & 269.7 \\
\hline 29 & 50 & 3.60 & 243.0 & 224.0 & 1.65 & 223.3 & 297. \\
\hline 30 & 60 & 3.11 & 219.0 & 227.7 & 1.68 & 284.7 & 251. \\
\hline Mean & 44.2 & & 229.0 & 235.7 & & 237.9 & 240 \\
\hline
\end{tabular}


TAELE 4

Graph reading: Time to perform, thousanths of a minute

\begin{tabular}{|c|c|c|c|c|c|c|c|}
\hline Sukㅣeㅗ & $\frac{\text { Level }}{(\underline{\underline{f}} \underline{\mathrm{c}})}$ & $\underline{\mathrm{B}} \angle \underline{\mathrm{R}}$ & 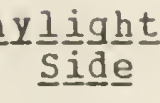 & T으 & $\underline{B} \angle \underline{R}$ & $=\underline{\underline{u}} \underline{\underline{\mathrm{S}}} \underline{\underline{\mathrm{S}}} \underline{\mathrm{e}} \underline{\mathrm{e}} \underline{\mathrm{d}}$ & Top \\
\hline 1 & 50 & 3.42 & 369.7 & 363.3 & 1.65 & 281.3 & 295.7 \\
\hline 2 & 40 & 4.67 & 248.3 & 281.3 & 1.69 & 287.3 & 240.3 \\
\hline 3 & 40 & 3.75 & 313.0 & 586.0 & 1.69 & 309.3 & 265.0 \\
\hline 4 & 30 & 5.73 & 288.0 & 316.0 & 1.67 & 211.0 & 235.0 \\
\hline 5 & 30 & 5.00 & 394.7 & 528.0 & 1.67 & 262.3 & 331.0 \\
\hline 6 & 32 & 4.90 & 165.3 & 195.7 & 1.65 & 273.7 & 274.0 \\
\hline 7 & 32 & 4.35 & 195.3 & 302.3 & 1.65 & 209.3 & 268.0 \\
\hline 8 & 32 & 4.84 & 252.3 & 238.7 & 1.65 & 237.0 & 360.3 \\
\hline 9 & 35 & 4.84 & 207.7 & 206.7 & 1.63 & 243.7 & 177.0 \\
\hline 10 & 40 & 4.71 & 497.0 & 327.0 & 1.69 & 396.0 & 583.0 \\
\hline 11 & 50 & 3.67 & 248.3 & 273.0 & 1.65 & 430.7 & 377.7 \\
\hline 12 & 65 & 3.33 & 316.7 & 270.0 & 1.69 & 425.3 & 318.3 \\
\hline 13 & 65 & 3.16 & 398.7 & 238.7 & 1.69 & 364.3 & 336.3 \\
\hline 14 & 40 & 3.30 & 410.3 & 454.0 & 1.69 & 388.0 & 341.0 \\
\hline 15 & 80 & 3.44 & 280.7 & 254.7 & 1.68 & 271.3 & 177.7 \\
\hline 16 & 40 & 4.29 & 318.3 & 388.0 & 1.69 & 322.0 & 387.7 \\
\hline 17 & 35 & 5.23 & 205.7 & 229.0 & 1.63 & 273.7 & 263.0 \\
\hline 18 & 35 & 2.63 & 560.7 & 402.0 & 1.63 & 246.7 & 294.3 \\
\hline 19 & 50 & 4.25 & 236.7 & 357.3 & 1.65 & 216.0 & 344.0 \\
\hline 20 & 50 & 3.88 & 310.3 & 338.0 & 1.65 & 350.7 & 263.3 \\
\hline 21 & 60 & 3.64 & 173.0 & 210.3 & 1.68 & 165.7 & 159.7 \\
\hline 22 & 50 & 3.57 & 217.3 & 179.3 & 1.65 & 249.3 & 183.7 \\
\hline 23 & 40 & 4.82 & 190.0 & 180.3 & 1.69 & 224.7 & 279.0 \\
\hline 24 & 40 & 4.62 & 330.3 & 347.0 & 1.69 & 439.0 & 405.3 \\
\hline 25 & 40 & 4.67 & 232.3 & 334.3 & 1.69 & 230.0 & 233.0 \\
\hline 26 & 35 & 4.57 & 193.0 & 171.3 & 1.63 & 202.3 & 268.0 \\
\hline 27 & 30 & 4.58 & 176.0 & 229.0 & 1.67 & 245.3 & 237.3 \\
\hline 28 & 50 & 3.63 & 207.3 & 190.7 & 1.65 & 159.7 & 292.3 \\
\hline 29 & 50 & 3.60 & 353.7 & 398.0 & 1.65 & 622.3 & 525.3 \\
\hline 30 & 60 & 3.11 & 433.3 & 579.7 & 1.68 & 496.7 & 468.3 \\
\hline Ye an & 44.2 & & 290.8 & 312.3 & & 301.1 & 306 \\
\hline
\end{tabular}


TA EL E 5

Prcofreading: Time to perform, thousanths of a minute

\begin{tabular}{|c|c|c|c|c|c|c|c|}
\hline Su 피른 & 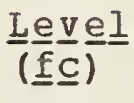 & $\underline{B} \angle \underline{R}$ & 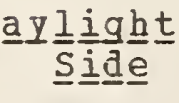 & Top & \multicolumn{3}{|c|}{ 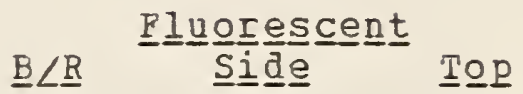 } \\
\hline 1 & 50 & 3.42 & 1036.5 & 1061.0 & 1.65 & 938.0 & 1093.0 \\
\hline 2 & 40 & 4.67 & 1255.5 & 1453.0 & 1.69 & 1335.5 & 1414.5 \\
\hline 3 & 40 & 3.75 & 1312.0 & 1551.0 & 1.69 & 1163.5 & 1050.5 \\
\hline 4 & 30 & 5.73 & 1076.5 & 1893.5 & 1.67 & 1469.0 & 1430.5 \\
\hline 5 & 30 & 5.00 & 1138.5 & 1010.5 & 1.67 & 877.5 & 971.5 \\
\hline 6 & 32 & 4.90 & 869.5 & 827.0 & 1.65 & 819.5 & 931.0 \\
\hline 7 & 32 & 4.35 & 974.5 & 800.5 & 1.65 & 1051.5 & 784.5 \\
\hline 8 & 32 & 4.84 & 940.5 & 1124.5 & 1.65 & 1135.0 & 1272.5 \\
\hline 9 & 35 & 4.84 & 581.0 & 591.0 & 1.63 & 648.0 & 654.0 \\
\hline 10 & 40 & 4.71 & 557.0 & 537.0 & 1.69 & 634.5 & 783.5 \\
\hline 11 & 50 & 3.67 & 777.5 & 800.0 & 1.65 & 904.0 & 793.0 \\
\hline 12 & 65 & 3.33 & 721.0 & 748.5 & 1.69 & 681.0 & 712.5 \\
\hline 13 & 65 & 3.16 & 1158.0 & 1074.5 & 1.69 & 904.0 & 1081.0 \\
\hline 14 & 40 & 3.30 & 927.5 & 886.5 & 1.69 & 999.5 & 883.5 \\
\hline 15 & 80 & 3.44 & 1862.0 & 1227.5 & 1.68 & 1300.0 & 1254.5 \\
\hline 16 & 40 & 4.29 & 1143.0 & 1233.0 & 1.69 & 1352.5 & 1536.5 \\
\hline 17 & 35 & 5.23 & 995.5 & 1015.5 & 1.63 & 1296.0 & 1218.5 \\
\hline 18 & 35 & 2.63 & 843.5 & 816.0 & 1.63 & 838.0 & 797.0 \\
\hline 19 & 50 & 4.25 & 1530.0 & 1263.5 & 1.65 & 1442.0 & 1505.5 \\
\hline 20 & 50 & 3.88 & 618.0 & 589.5 & 1.65 & 748.5 & 725.5 \\
\hline 21 & 60 & 3.64 & 693.0 & 642.0 & 1.68 & 586.5 & 636.5 \\
\hline 22 & 50 & 3.57 & 833.5 & 841.0 & 1.65 & 1327.5 & 1203.0 \\
\hline 23 & 40 & 4.82 & 1519.0 & 1463.5 & 1.69 & 1813.5 & 1345.0 \\
\hline 24 & 40 & 4.62 & 837.0 & 857.5 & 1.69 & 802.5 & 950.5 \\
\hline 25 & 40 & 4.67 & 1137.5 & 1193.5 & 1.69 & 1392.5 & 1519.5 \\
\hline 26 & 35 & 4.57 & 686.5 & 668.0 & 1.63 & 725.5 & 832 \\
\hline 27 & 30 & 4.58 & 743.5 & 949.0 & 1.67 & 1005.0 & 1022.0 \\
\hline 28 & 50 & 3.63 & 739.0 & 805.0 & 1.65 & 777.0 & 835.0 \\
\hline 29 & 50 & 3.60 & 1573.5 & 1390.5 & 1.65 & 1577.5 & 1765. \\
\hline 30 & 60 & 3.11 & 1303.0 & 1524.0 & 1.68 & 1430.0 & 1349. \\
\hline & 2 & & 1012 & 1027.9 & & 1065.8 & 0 \\
\hline
\end{tabular}


Daylight Fluorescent Mean

$\begin{array}{ccccc}\text { Need } 1 \in \text { Probing } & \text { Side } & 229.0 & 237.9 & 233.5 \\ & \text { Top } & 235.7 & 240.8 & 238.2 \\ & \text { Mean } & 232.4 & 239.4 & 235.9 \\ \text { Graph Reading } & \text { Side } & 290.8 & 301.1 & 296.0 \\ & \text { Top } & 312.3 & 306.1 & 309.2 \\ & \text { Hean } & 301.6 & 303.6 & 302.6 \\ & & 1012.8 & 1065.8 & 1039.3 \\ \text { Prcofreading } & \text { Side } & 1027.9 & 1078.4 & 1053.2 \\ & \text { Top } & 1020.4 & 1072.1 & 1046.2\end{array}$

Figure 8

Mean times to perform 


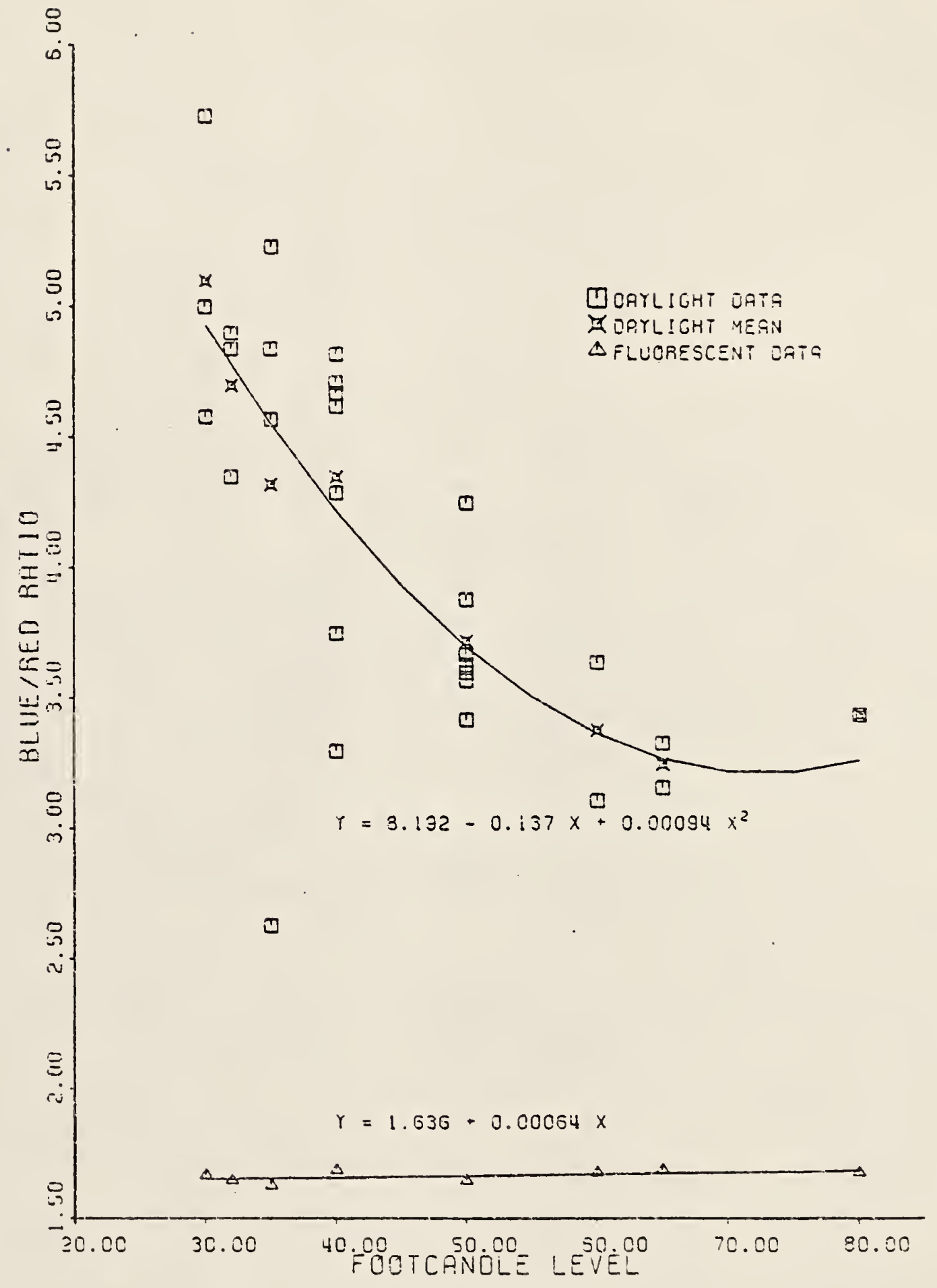

Fi. Eิure 9

Relationship of the Blue/Red ratio to illumination level 
TA ELE 6

Ne $€$ d€ probing: Subject's difficulty ratings

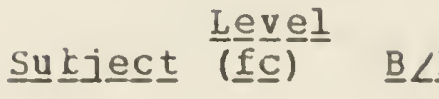

$\begin{array}{rr}1 & 50 \\ 2 & 40 \\ 3 & 40 \\ 4 & 30 \\ 5 & 30 \\ 6 & 32 \\ 7 & 32 \\ 8 & 32 \\ 9 & 35 \\ 10 & 40\end{array}$

1150

1265

1365

$14 \quad 40$

1580

$16 \quad 40$

$17 \quad 35$

$18 \quad 35$

1950

$20 \quad 50$

2160

2250

2340

$24 \quad 40$

$25 \quad 40$

$26 \quad 35$

$27 \quad 30$

$28 \quad 50$

$29 \quad 50$

$30 \quad 60$

Me an 44.2
3.42

4.67

3. 75

5. 73

5. 00

4. 90

4.35

4.84

4.84

4.71

3. 67

3. 33

3. 16

3. 30

3.44

4. 29

5.23

2.63

4. 25

3. 88

3. 64

3. 57

4.82

4.62

4.67

4. 57

4. 58

3. 63

3. 60

3. 11
12

17

11

13

13

10

13

8

10

11

13

9

8

16

13

14

10

13

13

9

11

6

10

10

11

13

15

8

12
7

10.1
므으

12

16

12

14

13

11

11

7

14

13

10

14

8

7

13

11

11

14

9

10

7

6

9

10

11

16

14

7

11
7

10.9

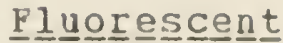
Side Top

\subsection{5}

1.69

1.69

1.67

1.67

1.65

1.65

1.65

1.63

1.69

1.65

1.69

1.69

1.69

1.68

1.69

1.63

1.63

1.65

1.65

1.68

1.65

1. 69

1.69

1.69

1.63

1.67

1.65

1.65

1.68

11

15

12

11

11

12

10

10

9

9

13

12

8

11

11

11

11

12

13

10

11

7

9

11

12

11

10

10

12

8

$10.6 \quad 10.4$ 
TAELE 7

Graph reading: Subject's difficulty ratings

\begin{tabular}{|c|c|c|c|c|c|c|c|}
\hline Su thject & 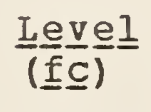 & $\underline{B} \angle \underline{B}$ & 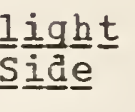 & T으모 & $\underline{B} \angle \underline{B}$ & 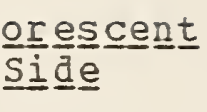 & T으모 \\
\hline 1 & 50 & 3.42 & 13 & 11 & 1.65 & 10 & 10 \\
\hline 2 & 40 & 4.67 & 13 & 14 & 1.69 & 12 & 10 \\
\hline 3 & 40 & 3.75 & 12 & 13 & 1.69 & 12 & 10 \\
\hline 4 & 30 & 5.73 & 12 & 15 & 1.67 & 10 & 10 \\
\hline 5 & 30 & 5.00 & 14 & 15 & 1.67 & 12 & 13 \\
\hline 6 & 32 & 4.90 & 10 & 11 & 1.65 & 12 & 12 \\
\hline 7 & 32 & 4.35 & 13 & 12 & 1.65 & 11 & 8 \\
\hline 8 & 32 & 4.84 & 9 & 8 & 1.65 & 11 & 14 \\
\hline 9 & 35 & 4.84 & 11 & 12 & 1.63 & 12 & 9 \\
\hline 10 & 40 & 4.71 & 12 & 10 & 1.69 & 11 & 10 \\
\hline 11 & 50 & 3.67 & 13 & 14 & 1.65 & 15 & 14 \\
\hline 12 & 65 & 3.33 & 12 & 13 & 1.69 & 15 & 11 \\
\hline 13 & 65 & 3.16 & 8 & 7 & 1.69 & 10 & 8 \\
\hline 14 & 40 & 3.30 & 11 & 13 & 1.69 & 17 & 13 \\
\hline 15 & 80 & 3.44 & 12 & 14 & 1.68 & 11 & 10 \\
\hline 16 & 40 & 4.29 & 13 & 11 & 1.69 & 10 & 11 \\
\hline 17 & 35 & 5.23 & 7 & 6 & 1.63 & 7 & 8 \\
\hline 18 & 35 & 2.63 & 12 & 11 & 1.63 & 11 & 10 \\
\hline 19 & 50 & 4.25 & 13 & 11 & 1.65 & 12 & 13 \\
\hline 20 & 50 & 3.88 & 15 & 12 & 1.65 & 13 & 11 \\
\hline 21 & 60 & 3.64 & 12 & 12 & 1.68 & 13 & 13 \\
\hline 22 & 50 & 3.57 & 9 & 10 & 1.65 & 15 & 11 \\
\hline 23 & 40 & 4.82 & 9 & 9 & 1.69 & 10 & 11 \\
\hline 24 & 40 & 4.62 & 12 & 12 & 1.69 & 15 & 16 \\
\hline 25 & 40 & 4.67 & 13 & 15 & 1.69 & 15 & 15 \\
\hline 26 & 35 & 4.57 & 9 & 12 & 1.63 & 13 & 18 \\
\hline 27 & 30 & 4.58 & 15 & 15 & 1.67 & 13 & 11 \\
\hline 28 & 50 & 3.63 & 8 & 7 & 1.65 & 9 & 15 \\
\hline 29 & 50 & 3.60 & 13 & 12 & 1.65 & 13 & 12 \\
\hline 30 & 60 & 3.11 & 7 & 8 & 1.68 & 7 & 6 \\
\hline & 44.2 & & 11.4 & 11.5 & & 11.9 & 11.4 \\
\hline
\end{tabular}


TA EL E 8

Prcofreading: Subject's difficulty ratings

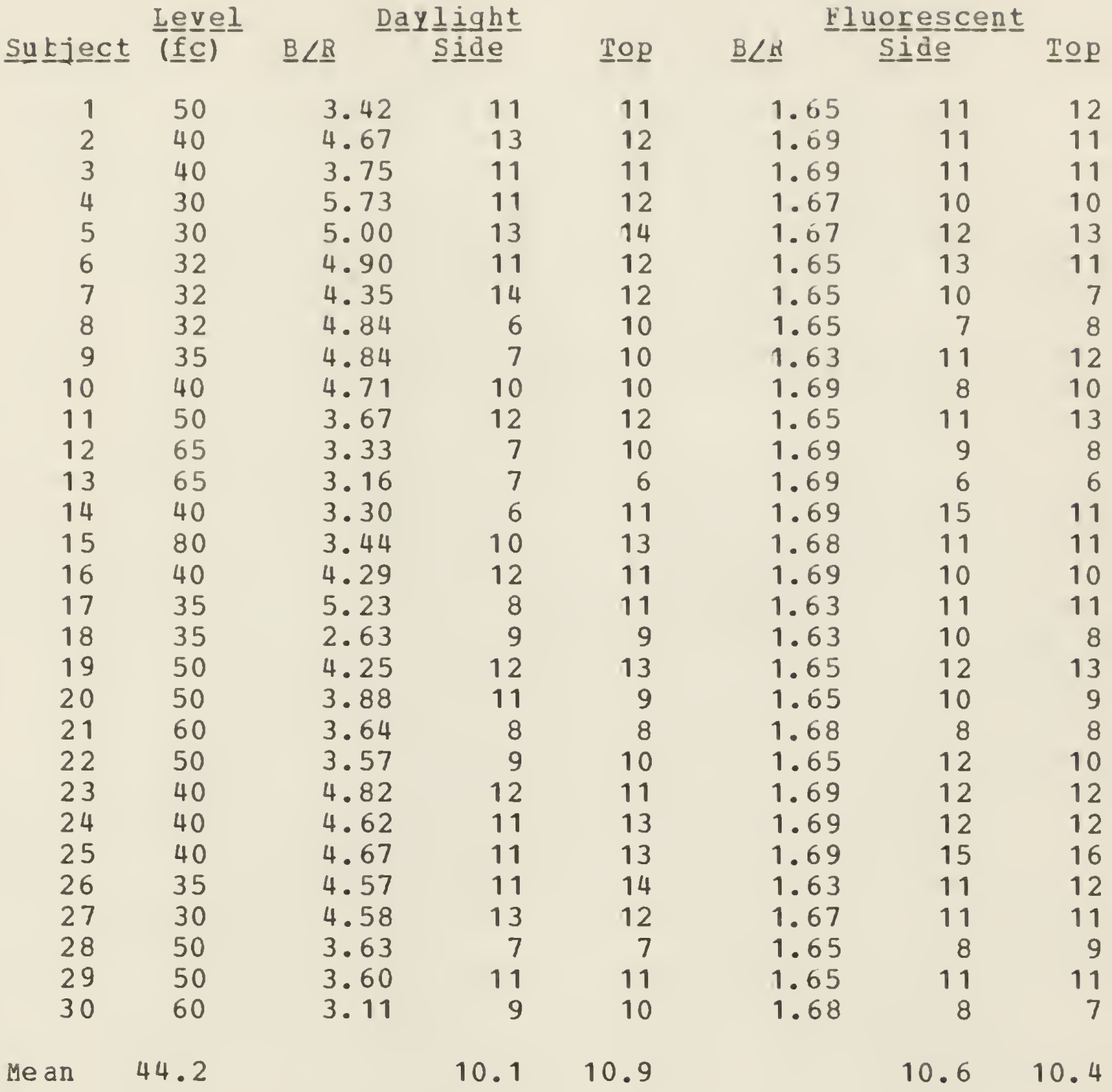


Daylight Fluorescent Mean

$\begin{array}{ccccc}\text { Ne } 1 \in \text { Probing } & \text { Side } & 10.1 & 10.6 & 10.4 \\ & \text { Top } & 10.9 & 10.4 & 10.7 \\ & \text { Nean } & 10.5 & 10.5 & 10.5 \\ \text { Graph Reading } & \text { Side } & 11.4 & 11.9 & 11.7 \\ & \text { Top } & 11.5 & 11.4 & 11.5 \\ & \text { Mean } & 11.5 & 11.7 & 11.6 \\ & & 10.1 & 10.6 & 10.4 \\ & \text { Side } & 10.9 & 10.4 & 10.7 \\ \text { Prcofreading } & \text { Top } & 10.5 & 10.5 & 10.5\end{array}$

Figure 10

Means of subject's difficulty ratings 
The marks for the semantic scales were given a number. being the left most possible mark numbe one, and the right most number seven. The results are presented in Tables 9 , 10. 11 and 12 for each one of the conditions studied.

The Statistical Analysis System (Barr, et al, 1976) prcgram was used to analyze the data. The results of the analyses of covariance run on the times to perform are presented on Tables 13, 14, and 15 .

The analyses of covariance on the Borg scales are Tatles 16, 17, and 18. The model included subject, source and angle (top-side) as main effects, and the source by angle interaction; the illumination level (FC in the model) interactions were used as covariates. Subject differences were significant at the 0.01 level in every analysis. The angle was significant at the 0.05 level for the graph reading task; source, angle, source*angle and fc*source*angle were significant at the 0.05 level for the prcofreading time. The source effect in the covariance analysis of the Borg scales for needie probing was significant at the 0.05 level.

Factor analysis was carried out on the semantic differential scales. Table 19 shows the correlation matrix of the scales. Table 20 presents the matrix of factor sccres with the explained variance. To explain more than 80 percent of the variance, five factors are retained. The scales with higher loadings for factor 1 are clear, bright, light and pleasant; no scale has a loading of .200 or more. 
TA ELE 9

Semantic differential ratings for Daylight (Side)

S

$\begin{array}{llll}\text { j } & \text { c } & \text { r } & \text { L } \\ & 1 & i & a\end{array}$

$\begin{array}{llll}e & e & g & r \\ c & a & h & g\end{array}$

$t \quad t \quad e$ $\begin{array}{llll}\text { u } & & \text { B } & \\ \mathrm{b} & \mathrm{C} & \mathrm{r} & \mathrm{L}\end{array}$

P

1

e

$\begin{array}{lllllll}1 & 2 & 2 & 7 & 7 & 3 & 3 \\ 2 & 5 & 3 & 4 & 4 & 6 & 6\end{array}$

$\begin{array}{lllllll}2 & 5 & 3 & 4 & 4 & 6 & 6 \\ 3 & 5 & 5 & 4 & 3 & 4 & 3\end{array}$

$\begin{array}{llllll}4 & 5 & 5 & 4 & 3 & 4 \\ 5 & 3 & 3 & 3 & 3 & 3\end{array}$

$\begin{array}{lll}5 & 5 & 5\end{array}$

$\begin{array}{lll}6 & 3 & 3 \\ 7 & 6 & 6\end{array}$

844

$\begin{array}{lll}9 & 1 & 2\end{array}$

$10 \quad 5 \quad 4$

1155

$\begin{array}{lll}12 & 1 & 4\end{array}$

$13 \quad 4 \quad 5$

$14 \quad 5 \quad 6$

$\begin{array}{lll}15 & 3 & 3\end{array}$

1636

$\begin{array}{lll}17 & 5 & 6\end{array}$

$\begin{array}{lll}18 & 4 & 6\end{array}$

$\begin{array}{lll}19 & 2 & 3\end{array}$

$20 \quad 4 \quad 3$

2134

$22 \quad 22$

2343

2444

$25 \quad 5 \quad 3$

$\begin{array}{lll}26 & 6 & 7\end{array}$

$27 \quad 5 \quad 6$

2866

2944

30
4

3

3

6

5

3

2

4

5

54

65

3

6

3

3

5

4

6

$6 \quad 6$

55

45

$\begin{array}{ll}3 & 3 \\ 3 & 3\end{array}$
4
5

$\begin{array}{lll}5 & 6 & 6 \\ 4 & 3 & 3\end{array}$

2

3

6

41

24

(1)

4

4

2

3

6

2

3

6 
TAELE 10

Serantic differential ratings for Daylight (Top)

\begin{tabular}{|c|c|c|c|c|c|c|c|c|c|c|}
\hline S & & & & & & $\begin{array}{l}\mathrm{p} \\
\mathrm{l}\end{array}$ & & & & N \\
\hline $\mathrm{u}$ & & B & & & & $\mathrm{e}$ & & & & a \\
\hline b & C & I & L & & & $\mathrm{a}$ & & G & C & $t$ \\
\hline$j$ & 1 & i & a & W & L & s & W & 1 & o & u \\
\hline e & e & g & I & $i$ & i & a & a & a & 1 & r \\
\hline c & $a$ & $\mathrm{~h}$ & g & d & k & $\mathrm{n}$ & I & I & o & a \\
\hline$t$ & r & $t$ & e & e & e & $t$ & m 1 & e & r & 1 \\
\hline -- & -- & -- & -- & -- & -- & -- & -- & -- & -- & - \\
\hline 1 & 2 & 4 & 7 & 7 & 3 & 3 & 4 & 3 & 5 & 4 \\
\hline 2 & 2 & 3 & 4 & 4 & 3 & 3 & 5 & 7 & 3 & 2 \\
\hline 3 & 6 & 5 & 5 & 5 & 5 & 5 & 5 & 2 & 4 & 5 \\
\hline 4 & 3 & 6 & 4 & 3 & 3 & 3 & 3 & 6 & 4 & 2 \\
\hline 5 & 3 & 5 & 3 & 4 & 5 & 3 & 4 & 6 & 7 & 2 \\
\hline 6 & 4 & 5 & 5 & 5 & 6 & 5 & 3 & 3 & 5 & 4 \\
\hline 7 & 5 & 5 & 4 & 6 & 4 & 5 & 4 & 5 & 5 & 4 \\
\hline 8 & 1 & 3 & 2 & 2 & 1 & 2 & 2 & 4 & 3 & 4 \\
\hline 9 & 6 & 6 & 5 & 6 & 5 & 4 & 5 & 7 & 6 & 3 \\
\hline 10 & 4 & 6 & 6 & 5 & 6 & 6 & 5 & 1 & 6 & 7 \\
\hline 11 & 3 & 2 & 3 & 2 & 3 & 2 & 3 & 2 & 5 & 2 \\
\hline 12 & 2 & 3 & 3 & 4 & 5 & 5 & 4 & 3 & 4 & 5 \\
\hline 13 & 3 & 5 & 4 & 5 & 3 & 3 & 4 & 5 & 5 & 2 \\
\hline 14 & 2 & 3 & 4 & 5 & 2 & 2 & 1 & 6 & 6 & 4 \\
\hline 15 & 5 & 5 & 4 & 4 & 4 & 5 & 4 & 5 & 5 & 4 \\
\hline 16 & 3 & 3 & 4 & 4 & 3 & 2 & 3 & 6 & 4 & 3 \\
\hline 17 & 6 & 5 & 3 & 4 & 4 & 4 & 6 & 4 & 6 & 5 \\
\hline 18 & 2 & 6 & 5 & 5 & 3 & 4 & 4 & 6 & 7 & 4 \\
\hline 19 & 1 & 3 & 3 & 4 & 4 & 1 & 2 & 7 & 4 & 6 \\
\hline 20 & 2 & 4 & 1 & 3 & 3 & 2 & 6 & 3 & 4 & 2 \\
\hline 21 & 2 & 2 & 2 & 2 & 2 & 2 & 3 & 4 & 3 & 3 \\
\hline 22 & 3 & 3 & 3 & 5 & 3 & 3 & 3 & 4 & 4 & 2 \\
\hline 23 & 3 & 4 & 5 & 3 & 3 & 3 & 4 & 5 & 5 & 3 \\
\hline 24 & 3 & 3 & 5 & 4 & 4 & 4 & 5 & 5 & 3 & 4 \\
\hline 25 & 2 & 3 & 3 & 4 & 1 & 2 & 3 & 6 & 6 & 1 \\
\hline 26 & 6 & 5 & 6 & 5 & 5 & 4 & 4 & 4 & 6 & 4 \\
\hline 27 & 6 & 5 & 5 & 4 & 6 & 5 & 6 & 5 & 4 & 5 \\
\hline 28 & 7 & 7 & 4 & 5 & 7 & 7 & 6 & 6 & 7 & 6 \\
\hline 29 & 3 & 3 & 3 & 3 & 3 & 3 & 3 & 6 & 4 & 3 \\
\hline 30 & 2 & 4 & 3 & 2 & 2 & 2 & 2 & 6 & 6 & 3 \\
\hline & 3.4 & 4.2 & 3.9 & 4.1 & 3.7 & 3.5 & 3.9 & 4.7 & 4.9 & 3.6 \\
\hline
\end{tabular}


TAELE 11

Semantic differential ratings for Fluorescent light (Side)

S

u

b C I

j $\quad 1 \quad i \quad a$

$\begin{array}{llll}e & e & g & r \\ c & a & h & g\end{array}$

$t \quad r \quad t \quad e$

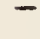

843

9
10

$\begin{array}{lll}10 & 4 & 4\end{array}$

$\begin{array}{lll}11 & 3 & 4\end{array}$

$12 \quad 2 \quad 4$

$\begin{array}{lll}13 & 2 & 3\end{array}$

$\begin{array}{lll}14 & 6 & 5\end{array}$

$\begin{array}{lll}15 & 3 & 3\end{array}$

$\begin{array}{lll}16 & 3 & 3\end{array}$

$\begin{array}{lll}17 & 5 & 4\end{array}$

$\begin{array}{lll}18 & 2 & 3\end{array}$

$19 \quad 2 \quad 5$

$20 \quad 5 \quad 4$

$21 \quad 4 \quad 4$

$22 \quad 3 \quad 4$

2333

$24 \quad 5 \quad 5$

$25 \quad 6 \quad 6$

$26 \quad 5 \quad 6$

$27 \quad 3 \quad 4$

$28 \quad 3 \quad 3$

296

30

5

$\mathrm{P}$
1
$\mathrm{e}$

e

$\begin{array}{lllll}a & G & C\end{array}$

$\begin{array}{lllllll}H & L & S & W & 1 & 0 & u\end{array}$

$\begin{array}{lllllll}i & i & a & a & a & 1 & I\end{array}$

$\begin{array}{lllllll}d & k & n & r & r & o & a\end{array}$

- - - - - - -

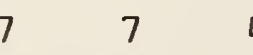

$4 \quad 4 \quad 2$

$3 \quad 3 \quad 5$

2

3

34

2

$\begin{array}{lll}6 & 5 & 5\end{array}$

32

44

3
3

7

44

42

63

$3-2$

33

3

4

3

4

4

4
3

4

6

4

4

4

6
5

4

3

4

4

2

$\begin{array}{llll}4 & 6 & 5 & 4\end{array}$

5

5

$\begin{array}{llll}2 & 2 & 3 & 2 \\ 5 & 2 & 6 & 7\end{array}$

$\begin{array}{llll}5 & 3 & 3 & 5\end{array}$

$\begin{array}{llll}6 & 5 & 6 & 5\end{array}$

5

5

5

2

3

6

4

5

3

3

33

3

2

$7 \quad 6$

33

4

6

$\begin{array}{llllll}3 & 3 & 6 & 6 & 6 & 3\end{array}$

$\begin{array}{llllll}4 & 1 & 2 & 7 & 4 & 6\end{array}$

$\begin{array}{llllll}2 & 2 & 4 & 5 & 3 & 1\end{array}$

2

43

4

4

3

5

4

4

45

6
5

3

6

$4 \quad 6 \quad 2$

253

$6 \quad 54$

445

275

523

444

$\begin{array}{lll}4 & 5 & 4\end{array}$

$\begin{array}{llllll}4 & 3 & 3 & 5 & 4 & 4 \\ 4 & 4 & 5 & 6 & 7 & 5\end{array}$

$\begin{array}{llllll}4 & 5 & 6 & 3 & 5 & 3\end{array}$

$\begin{array}{llllll}4 & 5 & 4 & 4 & 4 & 3\end{array}$

$\begin{array}{llllll}7 & 6 & 4 & 6 & 4 & 6\end{array}$

$\begin{array}{llllll}5 & 5 & 6 & 4 & 6 & 5\end{array}$

$\begin{array}{llllll}3 & 2 & 4 & 7 & 5 & 3\end{array}$

$\begin{array}{llllll}5 & 5 & 5 & 5 & 7 & 5\end{array}$

$\begin{array}{llllll}6 & 5 & 6 & 4 & 6 & 5\end{array}$

Hean

$$
\begin{array}{llllll}
3.9 & 3.8 & 4.0 & 4.0 & 3.8 & 3.9
\end{array}
$$

4.3

4.3

4.94 .2 
TA EL E 12

Se rartic differential ratings for Fluorescent light (Top)

\begin{tabular}{|c|c|c|c|c|c|c|c|c|c|}
\hline$S$ & & & & & 1 & & & & $N$ \\
\hline $\mathrm{u}$ & B & & & & $\mathrm{e}$ & & & & a \\
\hline C & r & L & & & $\mathrm{a}$ & & G & C & $t$ \\
\hline 1 & $i$ & $a$ & W & L & $\mathbf{s}$ & $W$ & 1 & 0 & $\mathrm{u}$ \\
\hline $\mathrm{e}$ & $\mathrm{g}$ & $r$ & $i$ & $i$ & $\mathrm{a}$ & a & $a$ & 1 & $r$ \\
\hline $\mathrm{a}$ & $\mathrm{h}$ & $\mathrm{g}$ & $\mathrm{d}$ & k & $\mathrm{n}$ & $r$ & r & o & a \\
\hline$r$ & $t$ & e & $\mathrm{e}$ & e & $t$ & m & e & I & 1 \\
\hline- & -- & -- & -- & -- & -- & -- & -- & -- & - \\
\hline 3 & 4 & 7 & 7 & 4 & 4 & 4 & 6 & 5 & \\
\hline 2 & 3 & 4 & 4 & 2 & 1 & 2 & 7 & 3 & \\
\hline 6 & 5 & 5 & 5 & 6 & 6 & 6 & 6 & 6 & \\
\hline 3 & 2 & 3 & 3 & 4 & 5 & 5 & 3 & 3 & \\
\hline 6 & 5 & 6 & 5 & 6 & 5 & 5 & 7 & 7 & \\
\hline 4 & 4 & 4 & 3 & 5 & 3 & 3 & 3 & 6 & \\
\hline 1 & 2 & 4 & 4 & 4 & 2 & 4 & 3 & 2 & \\
\hline 2 & 2 & 2 & 1 & 2 & 3 & 4 & 3 & 6 & \\
\hline 7 & 5 & 6 & 5 & 5 & 6 & 5 & 7 & 5 & \\
\hline 4 & 5 & 6 & 5 & 4 & 4 & 5 & 5 & 4 & \\
\hline 3 & 5 & 4 & 4 & 4 & 4 & 4 & 3 & 5 & \\
\hline 3 & 3 & 4 & 4 & 2 & 2 & 3 & 5 & 4 & \\
\hline 3 & 4 & 4 & 4 & 2 & 2 & 2 & 4 & 3 & \\
\hline 4 & 6 & 7 & 7 & 6 & 5 & 2 & 2 & 6 & \\
\hline 4 & 3 & 3 & 3 & 3 & 3 & 3 & 5 & 4 & \\
\hline 5 & 5 & 5 & 4 & 5 & 4 & 4 & 6 & 4 & \\
\hline 2 & 4 & 5 & 5 & 4 & 2 & 6 & 4 & 5 & \\
\hline 2 & 2 & 2 & 3 & 1 & 2 & 6 & 6 & 6 & \\
\hline 2 & 5 & 3 & 4 & 6 & 1 & 2 & 7 & 4 & \\
\hline 6 & 5 & 2 & 4 & 4 & 3 & 6 & 6 & 3 & \\
\hline 5 & 4 & 4 & 4 & 4 & 3 & 4 & 3 & 4 & \\
\hline 4 & 6 & 3 & 5 & 5 & 4 & 6 & 7 & 6 & \\
\hline 3 & 3 & 3 & 4 & 2 & 3 & 3 & 5 & 4 & \\
\hline 24 & 3 & 6 & 4 & 4 & 4 & 3 & 3 & 6 & \\
\hline 6 & 6 & 6 & 6 & 7 & 6 & 4 & 3 & 4 & \\
\hline 1 & 1 & 2 & 2 & 1 & 3 & 3 & 2 & 2 & \\
\hline 3 & 5 & 5 & 3 & 4 & 4 & 4 & 5 & 6 & \\
\hline 2 & 3 & 4 & 4 & 5 & 4 & 5 & 6 & 7 & \\
\hline 29 & 3 & 3 & 3 & 3 & 3 & 4 & 3 & 4 & \\
\hline 3 & 4 & 4 & 3 & 4 & 2 & 4 & 5 & 3 & \\
\hline
\end{tabular}

yean

$$
\begin{array}{lllllllllll}
3.6 & 3.9 & 4.2 & 4.1 & 3.9 & 3.4 & 4.0 & 4.7 & 4.6 & 4.1
\end{array}
$$


TAELE 13

Analysis of covariance on time to perform: Needle probing

으으므드르

Surject

Source

Angle

Source*Angle

F' * Source

FC*Angle

FC*Source*Angle

Error
$\underline{D F}$

28

1

1

1

1

1

1

84
모므므 의

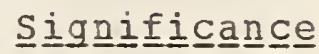

Sqquuㅡ므ㄹㅡㅗㅗ

$\underline{F}$

Leyㅡㄹ

0.0001

0.9462

5. 108

0.00

0.7707

95.423

0.09

0.7893

65.433

0.07

0.8092

8.486

0.06

0.9307

145.849

0.13

0.7186

++ Significant at the 0.01 level

+ Significant at the 0.05 level 
TAEL E 14

Analysis of covariance on time to perform: Graph reading

\section{Suㅡㅁㅛ 으}

S으므드므

surject

Source

Angle

Source*angle

FC*Source

F C*Angle

FC*Source*Angle

Error
$\underline{D E}$

Squㅡ므도오

28

834750.939

6.18

0.60

4. 31

20810.945

$$
655.095
$$

0.14

0.7134

1

3487.014

0.72

0.3976

1

1

84

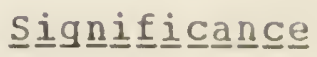

Levㅡㄹㅡ

++ Significant at the 0.01 level

+ Significant at the 0.05 level 
TAELE 15

Analysis of covariance on time to perform: Proofreading

S으므도드

Surject

source

Angle

Source*Angle

FC*Source

FC*Angle

FC*Source*angle

Error

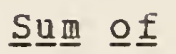

$\underline{D} \underline{F}$

Sq므므므ㄹㅡㅗㅗ

$\underline{\underline{E}}$

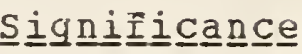

Leve

$\begin{array}{rrrrr}28 & 10218792.785 & 20.11 & 0.0001 \\ 1 & 109880.731 & 6.05 & 0.0159+ \\ 1 & 74240.326 & 4.09 & 0.0463+ \\ 1 & 86099.009 & 4.74 & 0.0322+ \\ 1 & 70727.653 & 3.90 & 0.0517 \\ 1 & 68507.412 & 3.77 & 0.0554 \\ 1 & 91388.846 & 5.04 & 0.0275+ \\ 84 & 1524517.170 & & \end{array}$

+t Significant at the 0.01 level

+ Significant at the 0.05 level 
TAELE 16

Analysis of covariance on subject's ratings: Needle probing

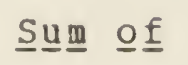

으으므돌

surject

source

Angle

Scurce*Angle

FC*Source

F c*angle

F' ${ }^{*}$ Source*Ang le

Error
$\underline{D} \underline{F}$

28

1

1

1

1

1

1

84

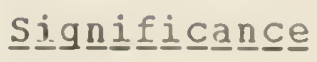

Sqgua $\underline{\text { re }} \underline{\text { s }}$

$\underline{F}$

L트므느

++ Significant at the 0.01 level

+ Significant at the 0.05 level 
TAELE 17

Analysis of covariance on subject's ratings: Graph reading

S으므드르

surject

source

Angle

Source*angle

FC*Source

FC*Angle

FC*Source*angle

EIIOI

$\underline{D F}$

28

1

1

1

1

1

1

84

++ Significant at the 0.01 level

+ Significant at the 0.05 level
모므므 으모

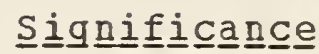

Sqquaㅡ드ㄹㅡㅗ

$\underline{F}$

Level

$\begin{array}{rrr}395.014 & 4.26 & 0.0001 \\ 0.008 & 0.00 & 0.9615 \\ 1.173 & 0.35 & 0.5534 \\ 0.337 & 0.10 & 0.7504 \\ 0.174 & 0.05 & 0.8193 \\ 1.956 & 0.59 & 0.4444 \\ 1.057 & 0.32 & 0.5736 \\ 278.238 & & \end{array}$


TAELE 18

Analysis of covariance on subject's ratings: Proofreading

\section{Suㅡㅁㅡ 으모}

S으브도드

surject

Source

Angle

Source*angle

FC*Source

F c*àngle

PC*Source*Angle

Error
$\underline{D} \underline{F}$

28

1

1

1

1

1

1

84
Sqquaㅡ므로

$\underline{F}$

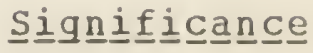

.

Lev르모

$\begin{array}{rll}299.798 & 5.62 & 0.0001 \\ 0.082 & 0.04 & 0.8358 \\ 0.132 & 0.07 & 0.7928 \\ 0.573 & 0.30 & 0.5847 \\ 0.074 & 0.04 & 0.8440 \\ 0.022 & 0.01 & 0.9143 \\ 0.003 & 0.00 & 0.9662 \\ 159.958 & & \end{array}$

++ Significant at the 0.01 level

+ Significant at the 0.05 level 


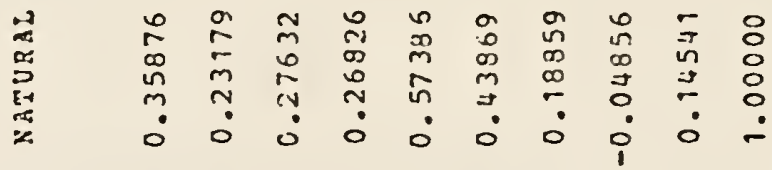

$\stackrel{ }{\sim}$

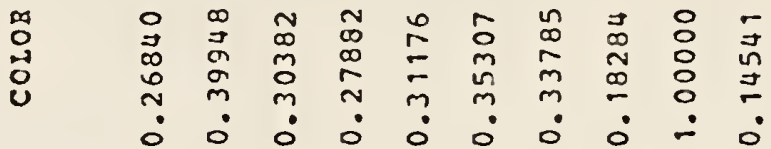

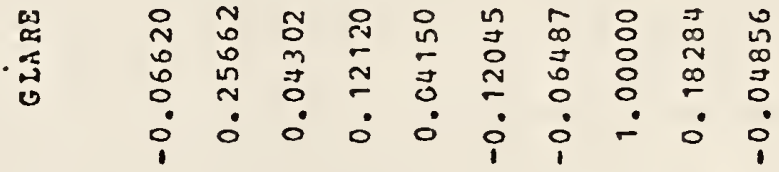

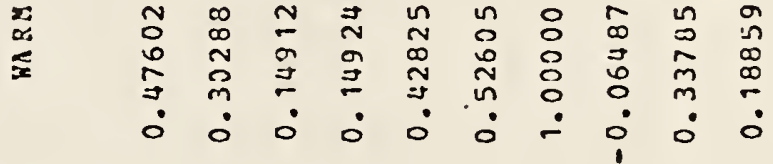

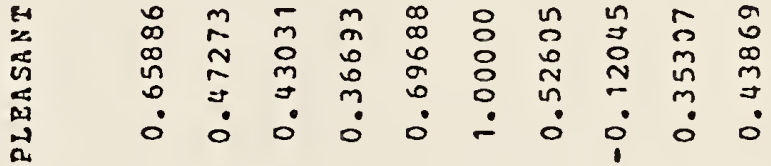

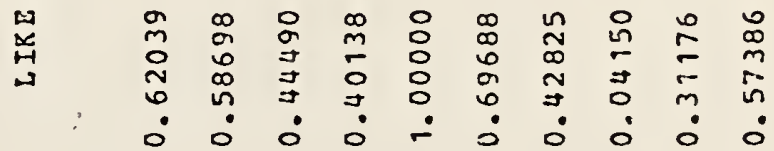

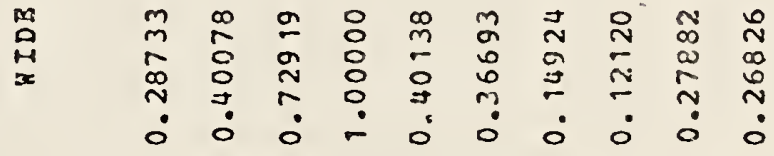

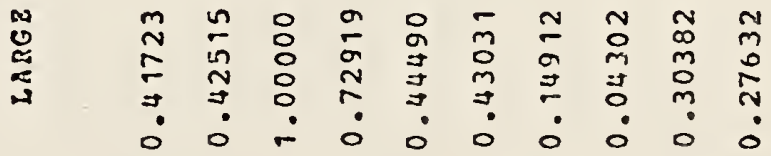

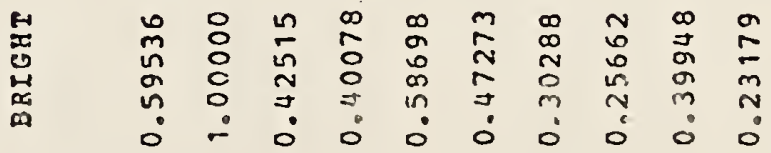

今

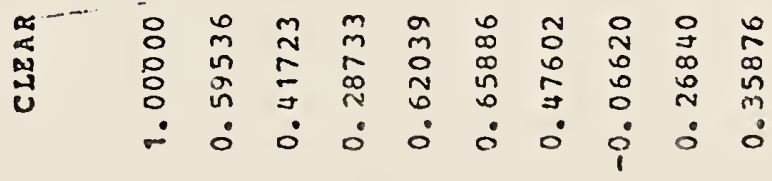

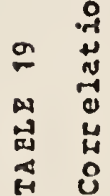

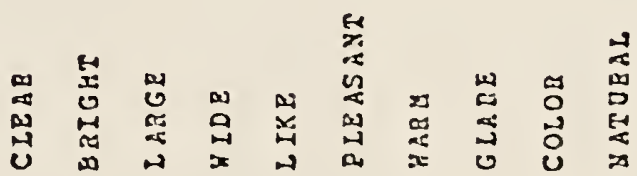


TAELE 20

Factcr pattern and explained variance

SCORING COEFPICIENT MATRIX

FACTOR 1 FACTOR2 FACTOR3 FACTOR4 FACTOR5

\begin{tabular}{|c|c|c|c|c|c|}
\hline CLEAR & 0.18259 & -0.18133 & 0.08720 & 0.00839 & -0.50632 \\
\hline BRIGHT & 0.17149 & c. 18005 & 0.22553 & 0.12157 & -0.50381 \\
\hline L A KGE & 0.15790 & 0.27219 & -0.40323 & -0.29698 & -0.05980 \\
\hline WILE & 0.14506 & 0.34067 & -0.39501 & -0.25216 & 0.06324 \\
\hline LIKE & 0.19677 & -0.10248 & -0.01649 & 0.32552 & -0.01428 \\
\hline PLEASANT & 0.19127 & -0.21955 & 0.01201 & -0.05548 & 0.00023 \\
\hline WARM & 0.13220 & -0.27757 & 0.38143 & -0.31989 & 0.11828 \\
\hline GIARE & 0.01490 & 0.52489 & 0.39715 & 0.48421 & -0.03118 \\
\hline COIOR & 0.12224 & 0.18705 & 0.38187 & -0.34609 & 0.74649 \\
\hline NATURAL & 0.13001 & -0.16920 & -0.27460 & 0.65404 & 0.58044 \\
\hline POFTION & 0.428 & 0.137 & 0.111 & 0.086 & 0.070 \\
\hline CUM PORTION & 0.428 & 0.565 & 0.676 & 0.762 & 0.832 \\
\hline
\end{tabular}


This factor was named clarity. For other factors high loadings are larger than .38. In factor 2 there is one scale with high loading: glare; this factor was named glare. High loadings in factor 3 occur with the large, wide, warm, glare and color scales; the factor was named spaciousness. The high loading scales in factor 4 are glare and natural; it was named natural. The scales with high loadings in factor 5 are clear, bright, color and natural; it was named color.

A covariance analysis was done on each one of the factors. These are Tables 21, 22, 23, 24, and 25 . No effect is significant for factor 1. subject is significant at the .01 level and source is at the 0.05 level for factor 2. The analysis of factor 3 does not give any significant effect. Subject is significant at the 0.01 level for factor 4. The significant effects for factor 5 are source at the 0.01 level and subject and fc*source at the 0.05 level.

The multivariate analysis was run for the five factors. Table 26 is the error sum of squares matrix. Table 27 is the sum of squares and test criteria for subject; it is significant at the 0.01 level. Table 28 is the sum of squares and test criteria for source; this effect is significant at the 0.05 level. The sum of squares and test criteria tables for angle and interactions are Tables 29 through 33. 
TAELE 21

Analysis of covariance on factors: Pactor 1 - Clarity

S으므도트

subject

source

Angle

Source*Angle

FC* Source

FC*Angle

FC*Source*Angle

Error

++ Significant at the 0.01 level

+ Significant at the 0.05 level

\section{Suㅡㅁㅡ 으트}

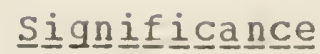

DEF $\quad$ Sguaㅡ므로 $\quad \underline{F} \quad \underline{\text { Le}} \underline{\text { vel }}$

$\begin{array}{rrrr}28 & 35.025 & 1.41 & 0.1174 \\ 1 & 0.154 & 0.17 & 0.6784 \\ 1 & 0.597 & 0.67 & 0.4145 \\ 1 & 0.088 & 0.10 & 0.7535 \\ 1 & 0.178 & 0.20 & 0.6554 \\ 1 & 0.295 & 0.33 & 0.5656 \\ 1 & 0.048 & 0.05 & 0.8157 \\ 84 & 74.552 & & \end{array}$

84

74.552 
TAELE 22

Analysis of covariance on factors: Factor 2 - Glare

Suㅡㅁㅡ 으토

으으모들

Subject

Source

Angle

Source*Angle

FC*Source

F C Angle

FC*Source*Angle

Error
DE

Sgquaㅡ므로

$\underline{P}$

28

53.887

2.625

3.95

2.559

3.86

0.097

0.15

1.970

2.97

1. 328

2.00

0.13

0.089

55.759

1

1

84

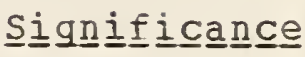

느므르

0.0001

0.0500

0.0529

0.7032

0.0886

++ Significant at the 0.01 level

+ Significant at the 0.05 level 
TAELE 23

Analysis of covariance on factors: Factor 3 - Spaciousness

\begin{tabular}{|c|c|c|c|c|}
\hline & & Suㅡㅁㅡ of & & Significicance \\
\hline S으모들 & $\underline{D} \underline{F}$ & Sguㅡ a드로 & $\underline{F}$ & Levㅡㄹ \\
\hline subject & 28 & 39.066 & 1.54 & 0.0682 \\
\hline Source & 1 & 0.402 & 0.44 & 0.5076 \\
\hline Angle & 1 & 0.451 & 0.50 & 0.4824 \\
\hline Source*Angle & 1 & 1.103 & 1.22 & 0.2732 \\
\hline FC*Source & 1 & 0.766 & 0.85 & 0.3606 \\
\hline FC*Angle & 1 & 0.361 & 0.40 & 0.5296 \\
\hline FC*Source*Angle & 1 & 0.842 & 0.93 & 0.3380 \\
\hline Error & 84 & 76.141 & & \\
\hline++ significant at & the 0.01 & level & & \\
\hline+ significant at & the 0.05 & level & & \\
\hline
\end{tabular}


TAELE 24

Analysis of covariance on factors: Factor 4 - Natural

Suㅡㅁㅡ 으

S으므도르

subject

source

Angle

Source*Angle

FC*Source

FC*Angle

FC*Source*Angle

Error
DE

Sgquaㅡ드로

$\underline{\underline{P}}$

28

1

1

1

1

1

1

84

63.069

3.57

0.0001

0.423

0.67

0.4151

0.058

0.09

0.7619

0.558

0.89

0.3492

0.709

1.13

0.2919

0.024

0.04

0.8468

0.349

0.55

0.4621

52.933

+t Significant at the 0.01 level

+ Significant at the 0.05 level 
TAEL E 25

Analysis of covariance on factors: Pactor 5 - Color

\section{Suㅡㅁㅡ 의}

Soㅡ므돌

subject

Source

Angle

Source*Angle

F c*Source

Fc*Angle

FC*Source*angle

Error

$\underline{D} \underline{F}$

28

42.975

5.666

0.092

0.196

1

1

4. 179

0.089

0.520

84

66.861
Sgguaㅡ모로

$\underline{\mathrm{P}}$

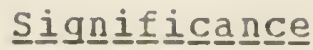

1.93

0.0115

7.12

0.0092

0.12

0.7343

0.25

0.6205

5.25

0.11

0.65

0.4211

++ Significant at the 0.01 level

+ Significant at the 0.05 level 
anova: 3r5or sua of squaras. and eross product atrix

$$
Z \text { - zввวв SSECP }
$$

$D E=84$

ZАCTOB 1

EACTOR 2

FACTOR3

8AC2034

8AC5025

\begin{tabular}{|c|c|c|c|c|c|}
\hline$P A=$ TOR 1 & 74.55197870 & -3.99938582 & -5.65105573 & 14.57325179 & -8.72602033 \\
\hline$P$ ACTCR2 & -3.99938582 & 55.75952747 & 12.27704212 & -4.35948196 & -11.08884795 \\
\hline BA=2083 & -5.65105573 & 12.27704212 & 76.14076474 & 4.67095550 & -11.76400879 \\
\hline PACTO 84 & 14.57325179 & -4.35948196 & 4.67098560 & 52.93361944 & -2.31734134 \\
\hline PSCTCa5 & -8.72602033 & -11.08884795 & -11.76400879 & -2.31734134 & 66.86111629 \\
\hline
\end{tabular}




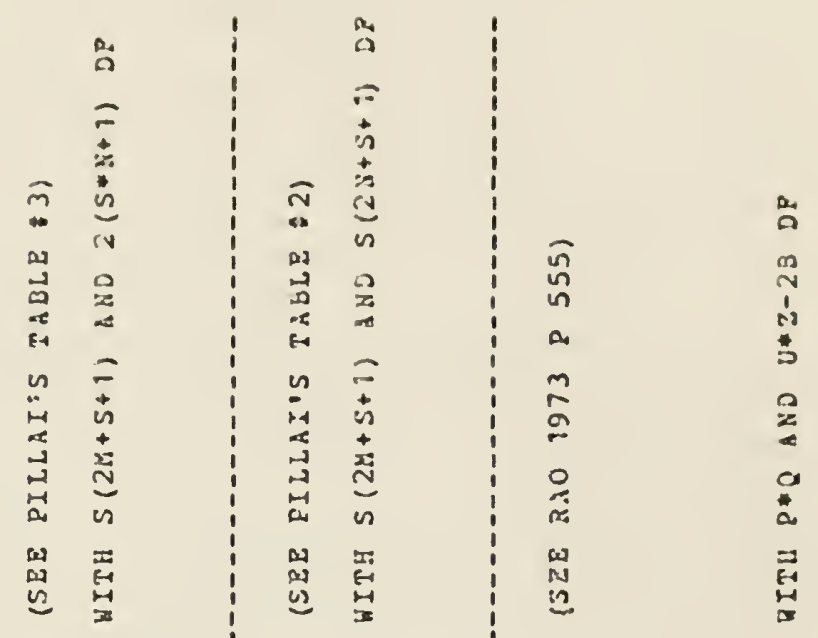
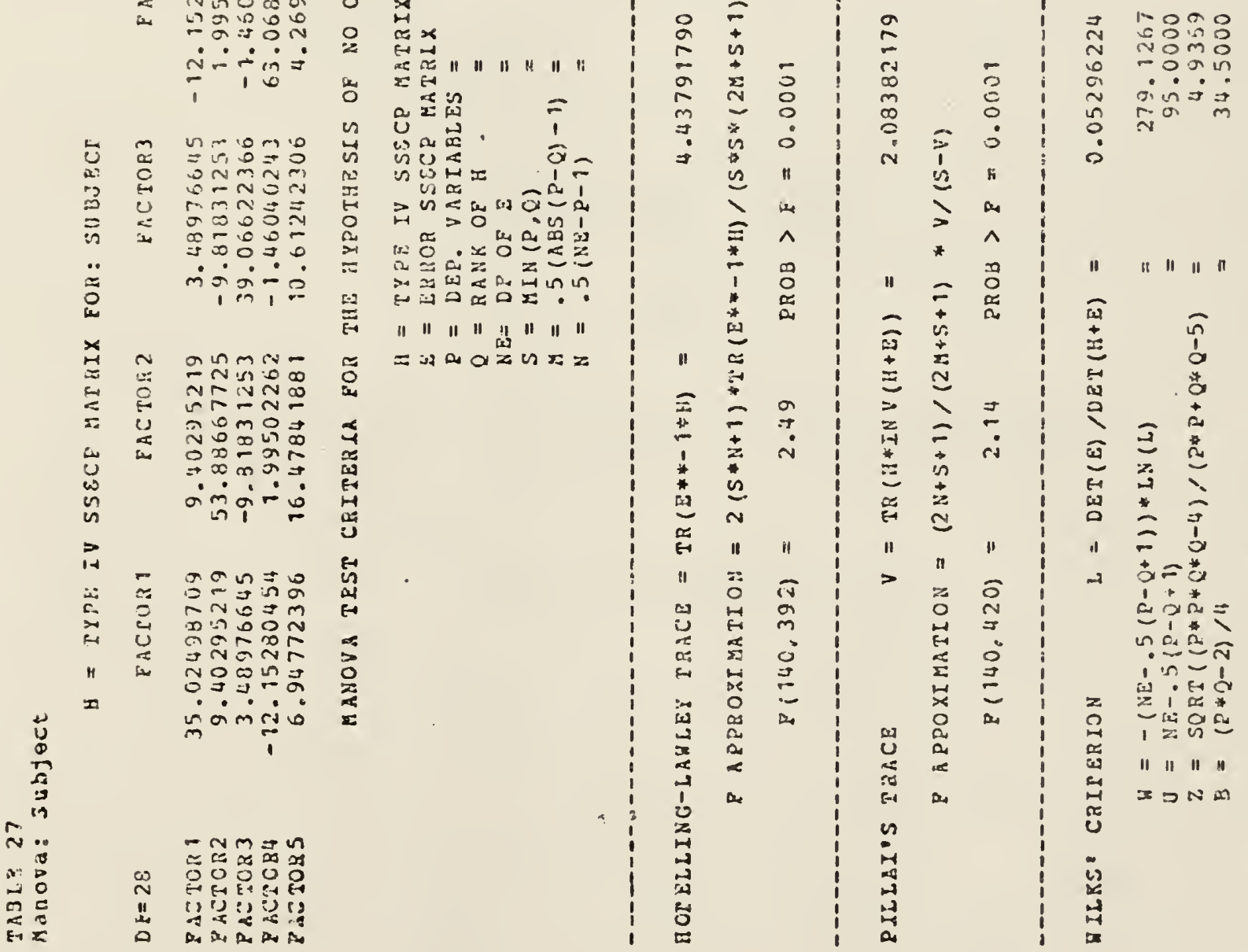


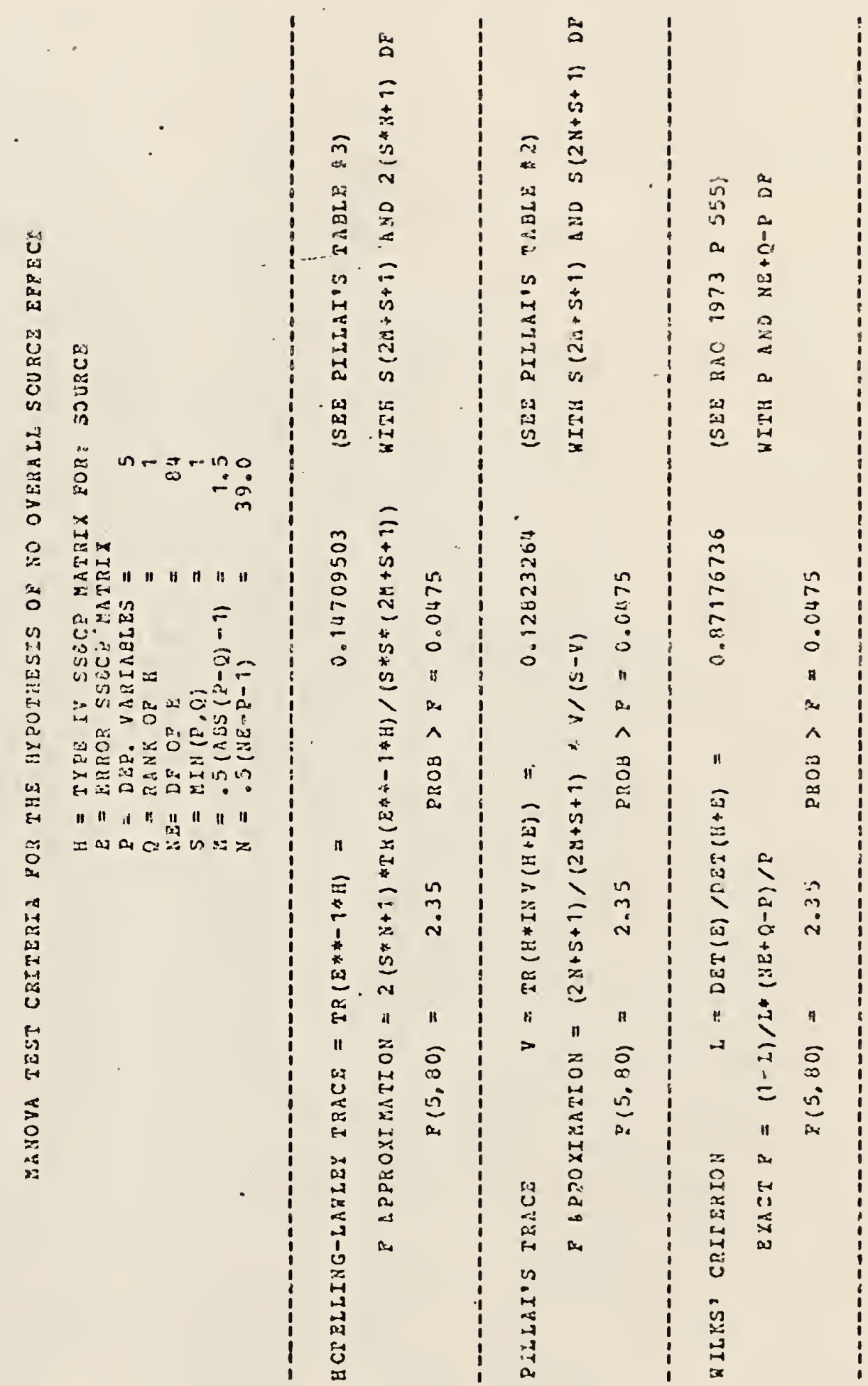


1
$o$
0
1

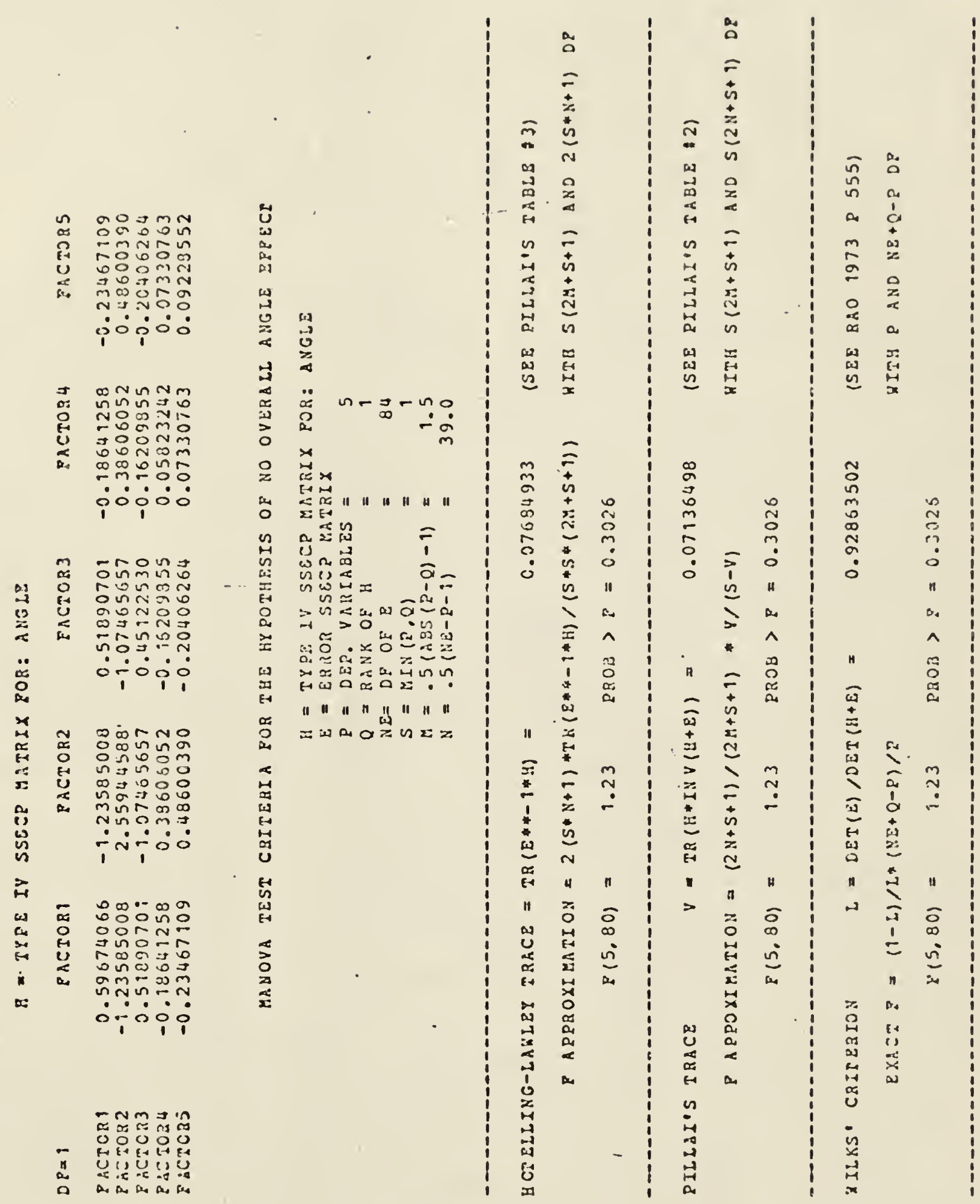


1ำ

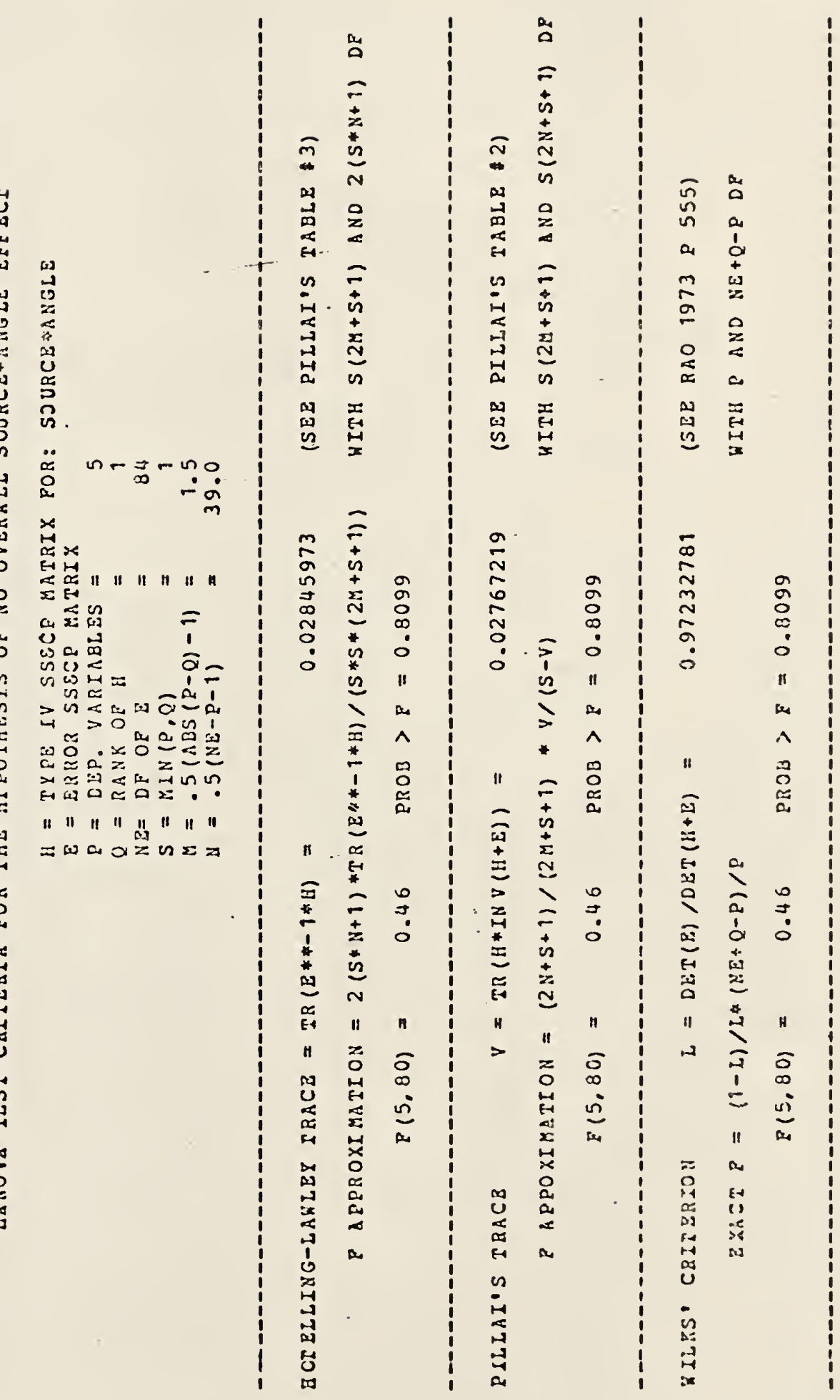


$\frac{1}{1}$
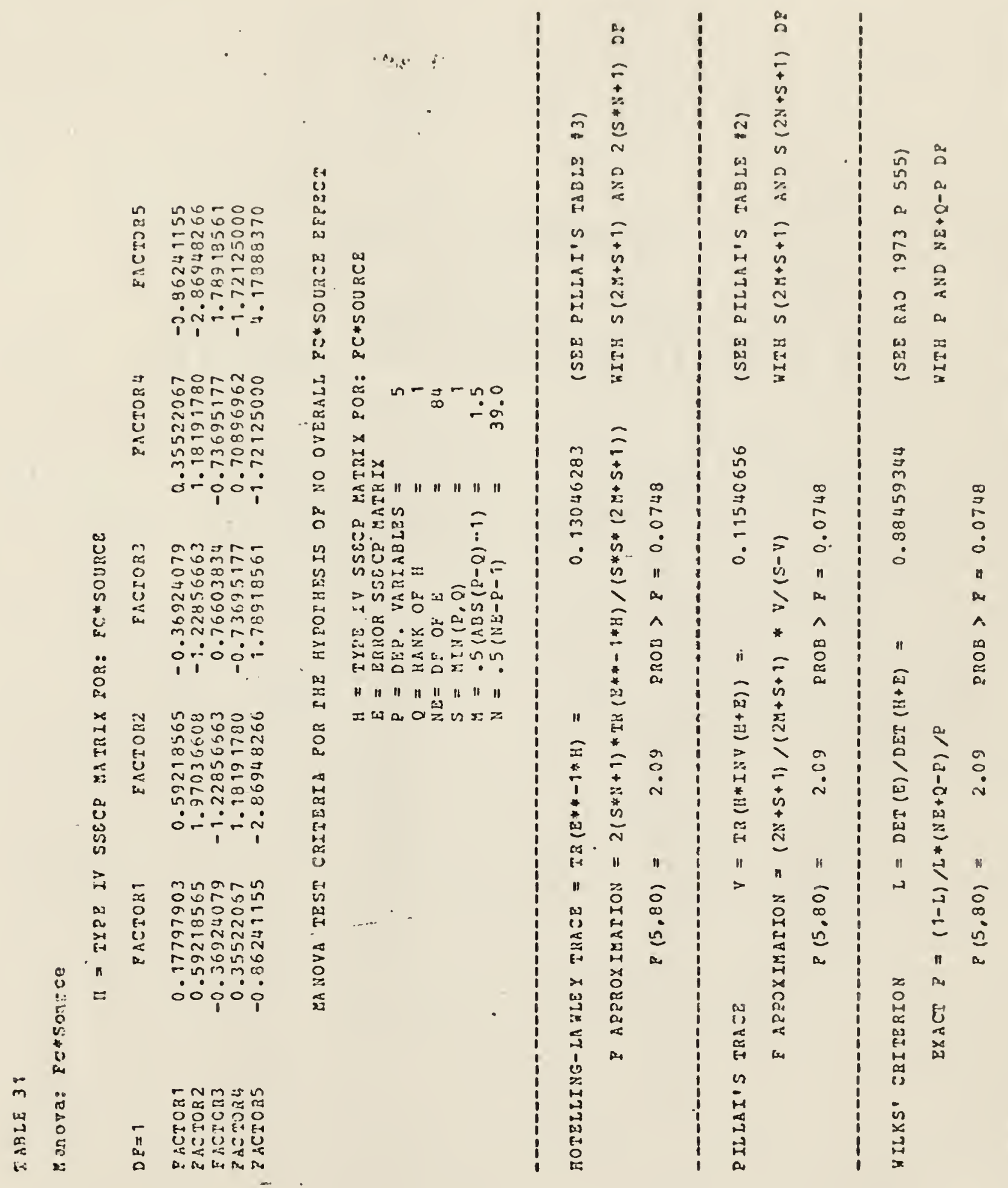
$\stackrel{1}{i}$

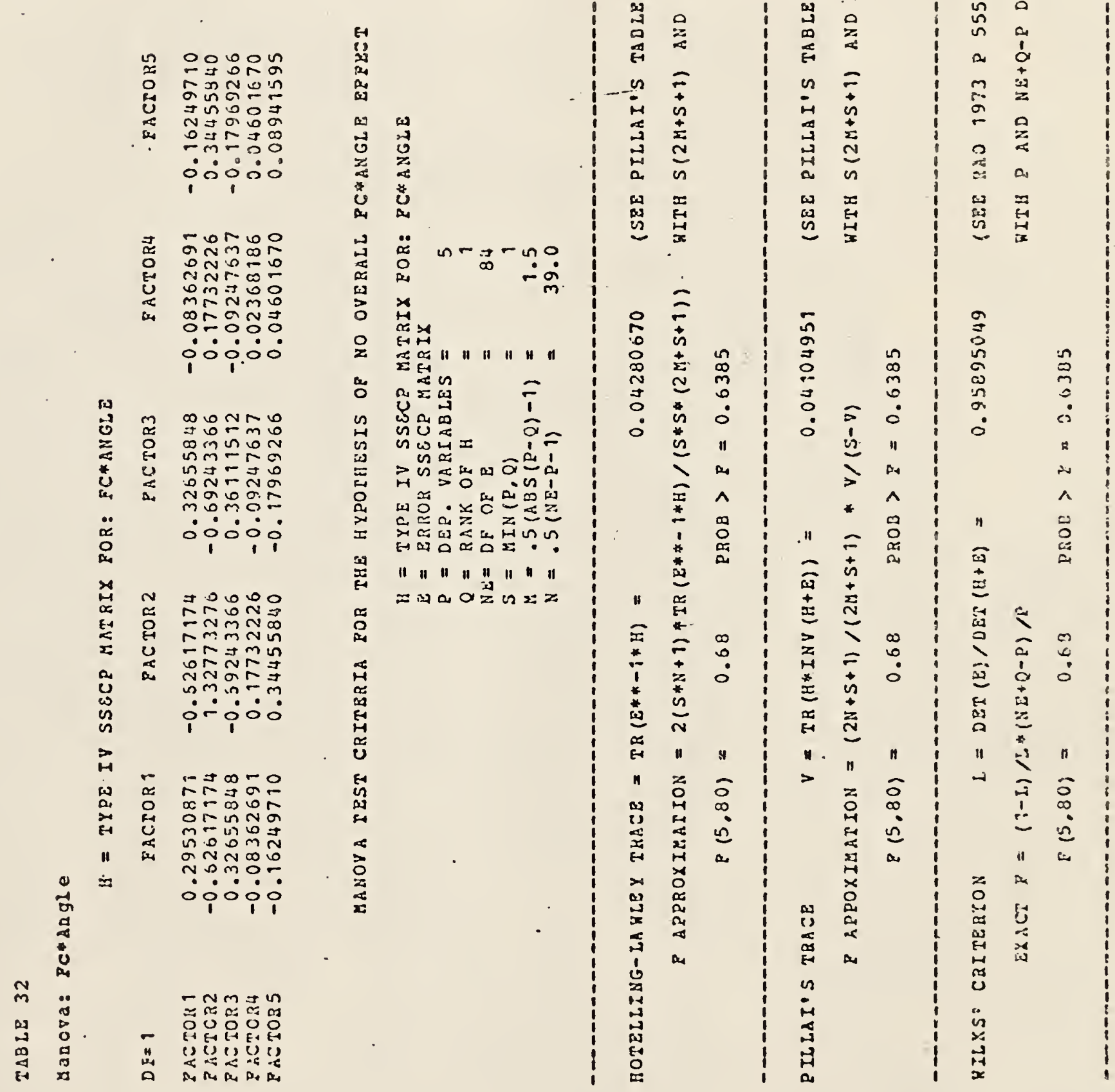




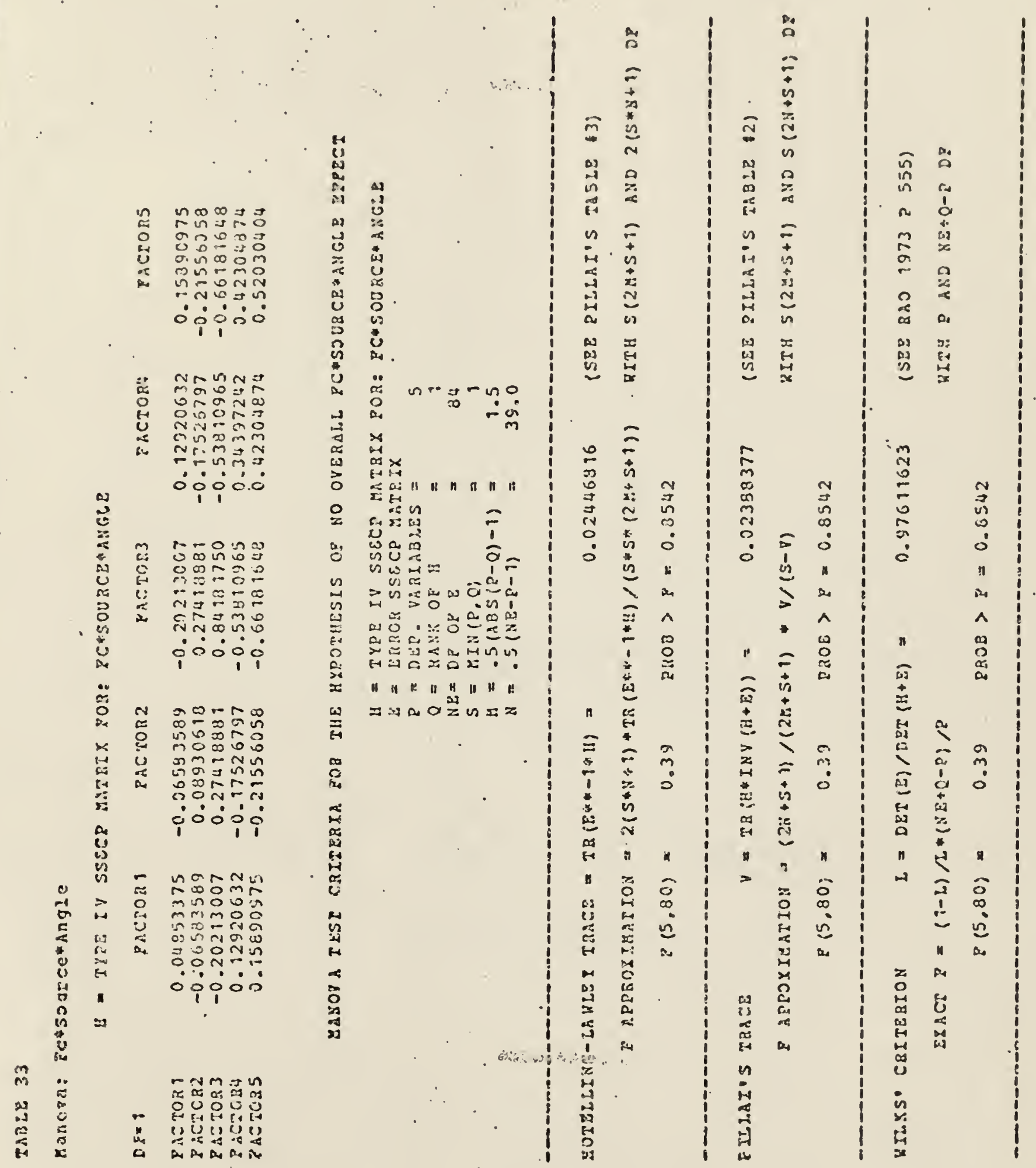


The correlation coefficient of time to perform with illumination was computed for the three tasks. It was also computed for the subject ratings of difficulty. These correlation coeffiecients and their significance level (Probability of $|R|>0$ ) are given in Table 34. No correlation coefficient is significant at the .05 level. Prcofreading time under daylight (side) exhitits the higher correlation coefficient; Proofreading under daylight (top) exhibits the higher correlation coefficient for the ratings. Figures 11 and 12 show the dispersion of the points. 
TAELE 34

Correlation coefficients and their significance level, for time to perform and subject's difficulty ratings

\begin{tabular}{|c|c|c|c|c|}
\hline & \multicolumn{2}{|c|}{ Dayli $\underline{i} q \underline{h} \underline{t}$} & \multicolumn{2}{|c|}{$\underline{\underline{F}} \underline{1} \underline{u}$ 으르로드르므t } \\
\hline & $\underline{\mathrm{s}} \underline{\mathrm{i}} \underline{\mathrm{d}} \underline{\mathrm{e}}$ & Tㅇp & $\underline{\text { Siq }} \underline{\text { de }}$ & T으 \\
\hline Needle Probing time & -0.066 & -0.027 & 0.016 & -0.043 \\
\hline Significance & 0.726 & 0.885 & 0.931 & 0.821 \\
\hline Graph Reading time & 0.130 & -0.032 & 0.299 & 0.000 \\
\hline Significance & 0.493 & 0.865 & 0.109 & 0.998 \\
\hline Prcofreading time & 0.323 & 0.000 & -0.002 & 0.022 \\
\hline Significance & 0.081 & 0.999 & 0.989 & 0.908 \\
\hline Ne $\in d \in$ probing rating & -0.295 & -0.290 & -0.114 & -0.019 \\
\hline Significance & 0.112 & 0.120 & 0.548 & 0.918 \\
\hline Graph Reading rating & -0.122 & -0.135 & -0.002 & -0.173 \\
\hline Significance & 0.519 & 0.475 & 0.993 & 0.360 \\
\hline rcofreading rating & -0.305 & -0.354 & -0.316 & -0.279 \\
\hline Significance & 0.101 & 0.055 & 0.089 & 0.134 \\
\hline
\end{tabular}




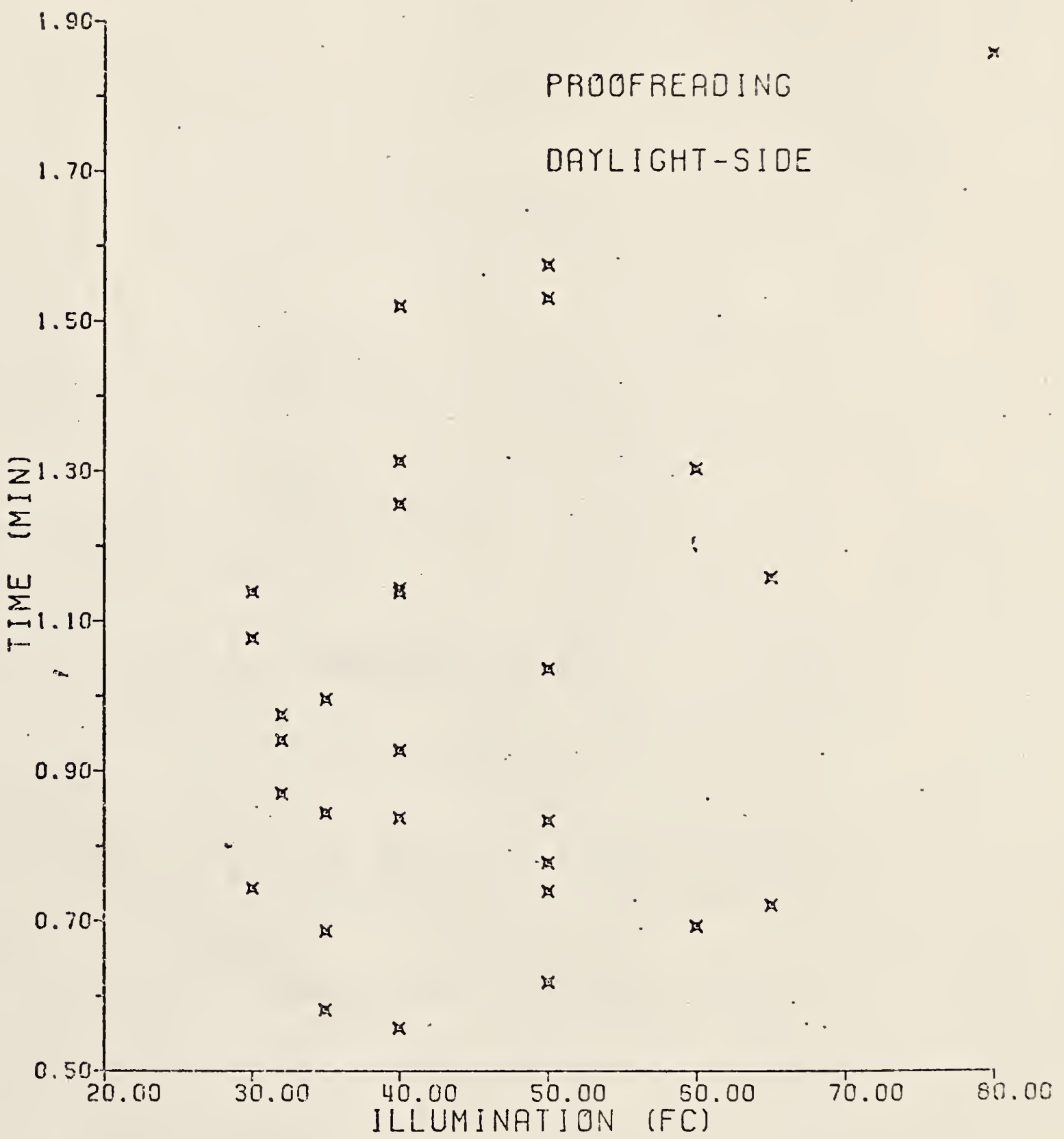

- Figure 11

Proofreading time vs illumination level, for davlight..side 


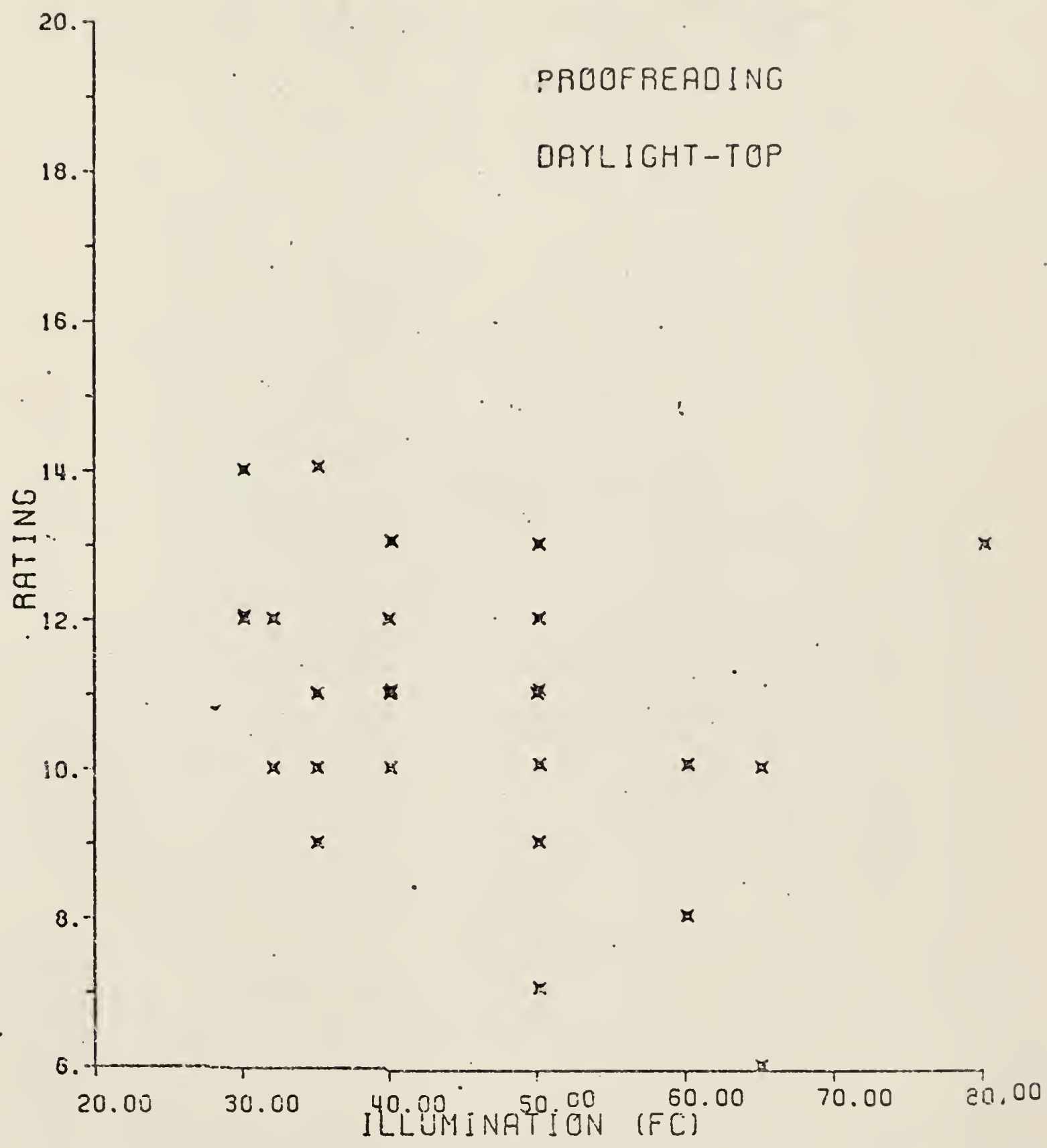

Figure 12

Proofreading ratings vs illumination lovel, for daylight-ton 


\section{DISCUSSION}

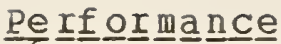

The data obtained for time to perform is presented in Takles 3, 4 and 5. The mean time for each condition follows the directional hypothesis: times are smaller for dalighting and for sidelighting. This is true for the three tasks. The data for the Borg scales (perceived difficulty) do not reveal the same trends (Tables 6, 7 and 8) Means are presented in Figures 8 and 10.

The results of the analyses on time to perform are Takles 13, 14 and 15. Subject differences are highly significant for the three tasks. This finding was expected, considering the differences among people. No other significant effect was found for the needle probing task. Angle wass significant for the graph reading task. Source, angle, source*angle and fc*source*angle were significant for the proofreading task.

The different findings are probable due to the differences in each task. The needle probing task is a highly dynamic three dimensional task that requires coordination and visual acuity. The graph reading and prcofreading tasks do not have the three dimensional characteristics of needle probing; they are basically flat, printed on paper. Contrast varied for each task. The position of the subject was not fixed; this circumstance is esfecially important for the needle probing. The demands of the last two tasks are also different; graph reading implied 
following a line on a grid, while proofreading implied recognizing similar letters in familiar words.

The angle effect is significant for the graph reading task; this might be due to veiling reflections. Performance is better for sidelighting than for toplighting for each source, and in the average (refer to pigure 8). This finding agrees with Griffith (1964), who stated that daylight from the side renders better contrast than overhead lighting systems. The difference in contrast found by Griffith is most likely due to the angle rather than the source. The hypothesis of better performance for sidelight has been corroborated by the results from this task. Source is not significant for this task.

several effects are significant for the proofreading task. The differences in the means indicate that daylight is better than fluorescent light; the superiority of sidelighting is also corroborated. These means are presented in Figure 8 . The best condition is daylight-side, the worst fluorescent-top. The results are not so simple; the interactions are significant (or very close to), and thus, a relationship exists between the source and the angle, and with the illumination level. There is the posibility (remote though) of a special set of conditions that froduced these results by chance.

The subject difficulty ratings have a wide range of responses. Subject effect is significant for the three tasks, as expected. The source effect is significant for 
ne de probing; this effect is due to the influence of the illumination level, as shown by the fcksource interaction. The fosition of the subject was not fixed, and subjects adcpted different positions. Subjects followed the same trend; they chose a position that offered visibility of maximum area of the needle eye. The background was then white ( the booth), and the task seemed easier at higher illumination levels (negative correlation coefficient). The ratings reflect differences in the perception of the source that changed with the illumination level.

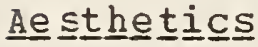

The semantic scales reveal a wide variety of responses. Table 19 shows the correlation among scales and Table 20 the factor scores. These tables are consistent, variables highly correlated have high loadings in the same factor.

Factors and scales were selected from previous research (Flynn, et al, 1973, others). The initial classification of scales and factors did not hold. All variables have small loadings in factor 1. There is a variable with exceedingly high loading in every one of factor 2,4 and 5 . Factor three has several scales with high loadings. The factor structure and variable loadings are shown in Figure 13. Factor 1 contains the scales selected from the factors evaluation and clarity, combined; it was named clarity. This factor does not have the same meaning as the clarity factor given by Flynn, et al, or other researchers. considering the low 


\begin{tabular}{|c|c|}
\hline \multicolumn{2}{|c|}{ Factor $1-$ Clarity } \\
\hline clear & 0.183 \\
\hline Bright & 0.171 \\
\hline Like & 0.197 \\
\hline \multirow[t]{2}{*}{ Pleasant } & 0.191 \\
\hline & Factor2 - Glare \\
\hline \multirow[t]{2}{*}{ Glare } & 0.525 \\
\hline & Factor3 - Spaciousness \\
\hline Large & 0.403 \\
\hline Wide & 0.395 \\
\hline \multirow[t]{2}{*}{ Warm } & 0.381 \\
\hline & Factor 4 - Natural \\
\hline \multirow[t]{2}{*}{ Natural } & 0.654 \\
\hline & Factor5 - Color \\
\hline Color & 0.746 \\
\hline
\end{tabular}


loadings of the scales, almost any name is suitable; this factor might be called "goodness of seeing", and as such shculd be understood. Factor 3 contains the scales associated with dimensions, plus the warm scale; it was named spaciousness. Every one of the remaining scales was highly loaded on a factor, and thus, these factors have been named: glare, natural and color. These differences with previcus research are due to the difference in the situation. Past studies had dealt with pleasant situations; the situations themselves were intended to be aesthetically pleasing. That is the case for real size rooms, scale models or displays. These situations always made use of a reference frame in the past experience of subjects. Different light modes were used to modify the features of the situations being seen and evaluated. The case is different in the present study. Subjects were placed in a special environment, they were asked to perform tasks and then asked strange questions; all of these within a little white cube while being observed: a rather unpleasing situation. The set-up was task oriented; the semantic scales were rated after performing under a particular condition, and subjects were judging an empty space, flat white, in which light itself was the main stimuli. The situation is uncommon and there is little chance for past experience to provide a reference frame. This lack of reference frame explains the small loadings and large explained variance of factor 1; subjects rated under a 
performance frame of mind (is it good enough to see and perform?), and thus, factor 1 identifies the "goodness of seeing" and was named clarity. The scales in factor 3 can be evaluated in the booth. They refer to dimensions. The physical dimensions of the booth were actually changed with the remotion of the roof, to allow light for the "top" angle. Three factors are derived from scales of what was initially called modifying influences. Natural and Color are closely related to light properties or appearance and then they could be evaluated in the booth.

Covariance analyses were run on these factors. Factor 2 (glare) shows significant differences for subject and source; angle and the fc*source interaction are close but not significant at the 0.05 level. Factor 4 (natural) shows significant differences for subject, and factor 5 (color) shcws significant differences for subject, source and fc*source. Table 35 presents the factor means by conditions and by source. It should be kept in mind that the factors are linear combinations of the scales, and as such, they include effects from every scale. This fact raises some obstacles in the interpretation of the results. It is also true that scales with high loadings are directly linked to the factors. Factor 2 (glare) has higher means for daylight: since high values on the glare-nonglare scale are toward nonglare, it can be concluded that daylight is less glaring than fluorescent light. In the same way, factor 5 (color) has smaller means for daylight, and thus it is 
TAELE 35

Factor means by condition and source

\begin{tabular}{|c|c|c|c|c|}
\hline & \multicolumn{2}{|c|}{ Dayㅣㅁㅗhㅡt } & \multicolumn{2}{|c|}{ 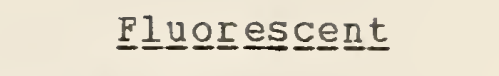 } \\
\hline & $\underline{\text { side }} \underline{\mathrm{e}}$ & Top & $\underline{\text { S }} \underline{i} \underline{d} \underline{e}$ & T으모 \\
\hline \multirow[t]{2}{*}{ Factor 1-clarity } & 0.109 & -0.120 & 0.062 & -0.051 \\
\hline & \multicolumn{2}{|c|}{-0.005} & \multicolumn{2}{|c|}{0.005} \\
\hline \multirow[t]{2}{*}{ Factor 2-Glare } & -0.085 & 0.268 & -0.252 & 0.068 \\
\hline & \multicolumn{2}{|c|}{0.092} & \multicolumn{2}{|c|}{-0.092} \\
\hline \multirow[t]{2}{*}{ Factor3-spaciousness } & 0.047 & 0.098 & 0.016 & -0.161 \\
\hline & \multicolumn{2}{|c|}{0.072} & \multicolumn{2}{|c|}{-0.072} \\
\hline \multirow[t]{2}{*}{ Factor4-Natural } & -0.025 & -0.086 & -0.039 & 0.150 \\
\hline & \multicolumn{2}{|c|}{-0.056} & \multicolumn{2}{|c|}{0.056} \\
\hline \multirow[t]{2}{*}{ Factor 5-Color } & -0.233 & -0.049 & 0.223 & 0.059 \\
\hline & \multicolumn{2}{|c|}{-0.141} & \multicolumn{2}{|c|}{0.141} \\
\hline
\end{tabular}


considered more colorful than fluorescent light; the positive characteristics of the scales are toward small nuabers. This difference is affected by the illumination level as shown by the fc*source interaction.

The multivariate analysis of covariance was run on these factors. Significant effects were subject and source. This corroborates the fact of different individual preferences. The multivariate analysis considers all five factors; the result indicates that sources were perceived differently. The results of the covariance analysis, and the factor means, led to the conclusion that daylight is preferred to fluorescent light. This finding confirms the hyfothesis that user impressions favor daylight.

angle was neither significant in the covariant analysis, nor in the multivariate. The hypothesis that sidelight would be preferred over toplight was not conficmed.

It has been stated that subject and illumination effects are confounded. Table 34 presents the Pearson correlation coefficients for the time to perform and the surject difficulty ratings, for each one of the tasks. There is no coefficient significant at the 0.05 level. The prcofreading task, under daylight-side condition, exhibits the best correlation coefficient for the times to perform. The experimental data points are plotted in Figure 11 as a 
function of the illumination level. A wide dispersion of the points is observable. Figure 12 is the plot of the prcofreading ratings versus illumination, for the condition with the best correlation coefficient, daylight-top. There is also a complete dispersion of points. These two figures are illustrative samples, selected for baving the best correlation coefficients. Some factors are to be considered, such as subject differences, and the small range of illumination levels. Past research relating illumination level and performance has involved a wider range of illumination levels. The results presented by other investigators that used similar tasks ( Smith, 1976, 1978, Chitlangia, 1976) show a flat or almost flat function for the range of illumination levels usea in this study. The small range of illumination levels and the fact that a subject performed under one illumination level confound sulject and illumination effects in the model.

The fact that the two sources are different is obvious. Daylight has a continuous wavelength distribution as opposed to the fluorescent discrete distribution. The color teaperature of the sources differ considerably, with daylight cooler (north window) as shown in Figure 9. Sources were perceived as different by subjects as shown by the analyses of the factors. The set-up was intended to mask the sources and avoid subject's reactions toward the hypotheses; the objective was accomplished, as revealed by informal talk with the subjects after performance. Daylight 
was subjectively preferred as the factor means show. The analysis of the tasks did not prove any superiority of daylight as a source. However, the fact that performance was tetter for sidelighting, indirectly favors daylight since it usually comes from side windows. Daylight is more difficult to control than fluorescent light, and thus, designers prefer the latter to the former. The decision to use or exclude daylight should be economical, considering non-economical factors such as the advantages of sidelighting and user impressions. The purpose of this research was to study the short term effect of daylighting. Ps pchological reactions and biological effects have been reforted by collins (1975) and wurtman (1968). The study of these long term effects is beyond the scope of this research.

some considerations for future research are the characteristics of the tasks. They should minimize response limitation. For example the proofreading task intended to measure performance by the time only; a different design is recommended considering both time and errors, independently and ccmbined by a relationship of some sort, relieving the subject of the burden of a minimum requirement. The type of task deserves further consideration. In this study, the "flat" tasks showed some light effects. These flat tasks ar $€$ mcre typical of office situations. The tasks used could be modified, and/or new ones included. Some factors to consider are dimensional characteristics of the task, 
sulject position, background, control of illumination level. Future research could also consider different sources, different daplight direction (ie. south window), different illumination levels and a wider range.

Future study of aesthetics of daylight call for modifications in the set-up. Real size or scale models shculd be used, to provide a reference frame for the judgements of the subjects. The study could use geometrical forms and figures, and different lighting modes to study modeling effects. Future research should include tasks for which color is relevant, a variable that was not considered in this study. 
CONCLUSION

The main objective, to evaluate daylight as a light source was accomplished. Some conclusions can be drawn upon this research.

1. Subject differences are an important factor to consider in lighting research.

2. The hypothesis of better performance under daylight was nct confirmed.

3. The hypothesis of better performance for sidelighting was confirmed for some tasks. These were basically flat tasks. The effect was attributed to veiling reflections.

4. Pactor analysis identified a scale pattern different from the expected. The factors are explained by the task orientation of the subjects and set-up.

5. The hypothesis that user impressions, categorized by the factors, favors daylight was confirmed.

6. The hypothesis that sidelighting is preferred was not confirmed. 
BIBLIOGRAPHY

BaII, A. J., Goodnight, J. H., Sall, J. P. and Helwig, J. T.

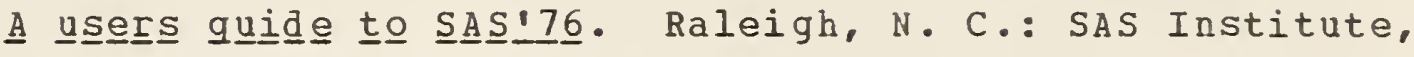
1976.

Bennett, C. A., Ali, P. A., Perecherla, A and Rubison, R. M., Two studies of lighting aesthetics, Procedings of the Human Factors Society, Detroit, October 1978

Bennett, C. A., Chitlangia, A. and Pangrekar, A. Illumination levels and performance of practical visual tasks, Kansas State Experimental Station, Report 125, Fal1 1978

Blackwell, H. R. Brightness discrimination data for the

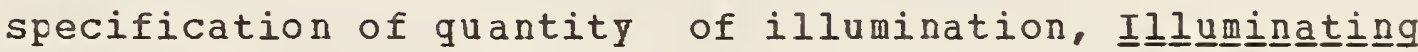

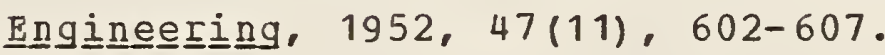

Blackwell, H. R., Development and use of a quantitative method for specification of illumination levels on the

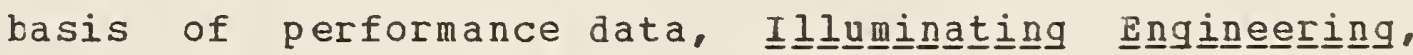
$1959,54(6), 317-353$.

Blackwell, H. R. and Scott, D. E., Analysis of visual performance data obtained in a Landolt ring task without

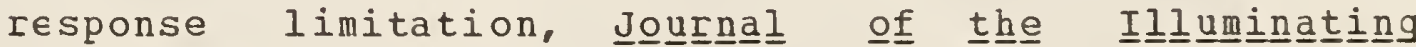




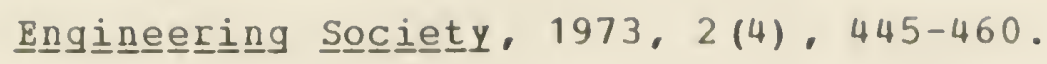

Boyntcn, R. M. and Boss, D. E. The effect of background luminance and contrast upon visual performance

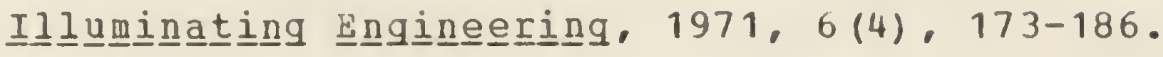

Chit langia, A. Relation between illumination level and visual performance. Unpublished master thesis, Kansas State University, 1976.

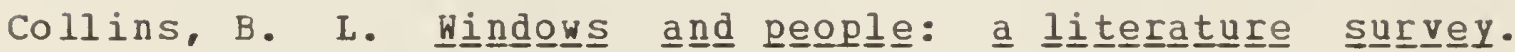
Washington: National Bureau of Standards (U.S.), 1975.

Comittee on daylighting of the IES, Recommended practice of

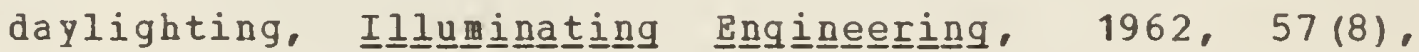
$517-557$.

Delaney, W. B., Hughes, P. C., McNelis, J. F. and Soules, T. F., An examination of visual clarity with high color

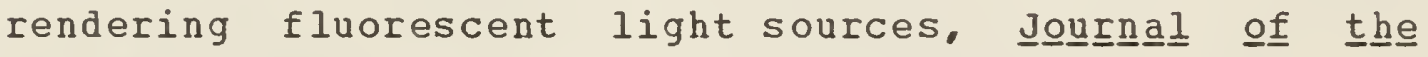

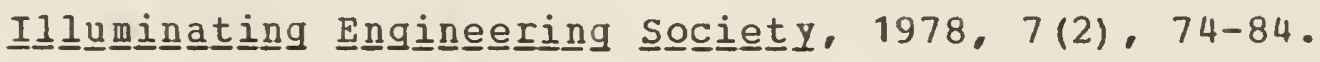

Faulkner, T. W. and Murphy, T. J., Lighting for difficult visual tasks, 브므ㅁㅡㅡㅡ 트므트으토, 1973, 15(2), 149-162.

Flynn, J. E., Spencer, T. J., Martyniuk, O. and Hendrick, C. Interim study of procedures for investigating the 
effect of light on impression and behavior, 프브므므므 으 the Ill umingating Engineering Society, 1973, $3(1), 87-94$.

Flynn, J. E. and Spencer, T. J., The effect of light source cclor on user impression and satisfaction, 프므므믈 으

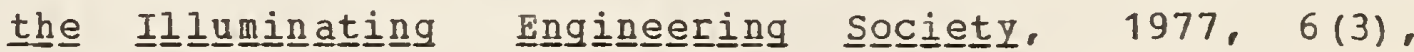
$167-179$.

Flynn, J. E., Hendrick, C., Spencer, T. and Martyniuk, O., A guide to methodology procedures for measuring subjective impressions in lighting, 프므므므 of

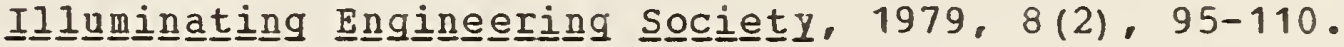

Pry, G. A., Assesment of visual performance, I 1 lumina

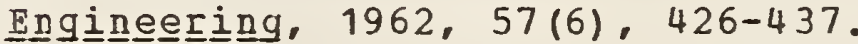

Griffith, J. W., Analysis of reflected glare and $\nabla$ isual

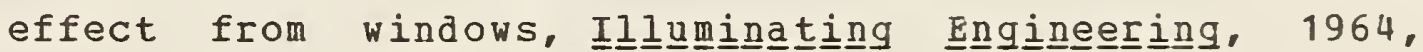
$59(3), 184-188$.

Griffith, J. W., Resource optimization calls for Analysis

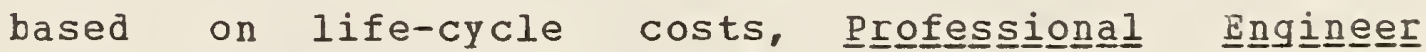

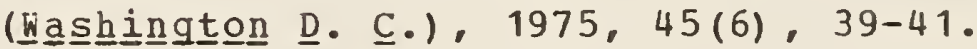

Griffith, J. W., Benefits of daylighting: cost and energy

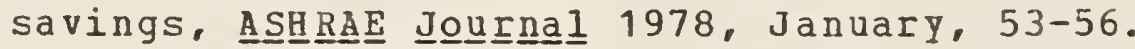


Hawkes, R. J., Loe, D. L. and Rowlands, E., A note toward

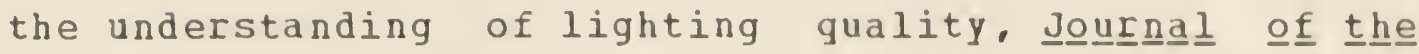

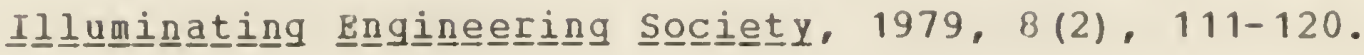

Henderson, R. L., McNelis, J.F. and Williams, H. G., A survey and analysis of important visual tasks in

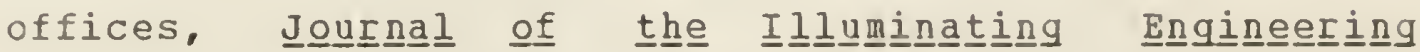
Sọcieㅌ․ $1975,4(2), 150-153$.

Hollwich, F., Dieckhues, D, and Meiviers, C. O., The physiological significance of light for human beings,

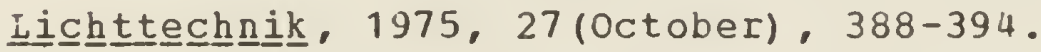

Hofkinson, R. G., Petherbridge, P. and Longmore, J.

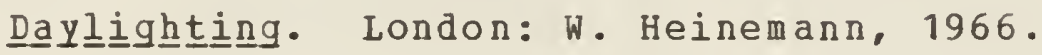

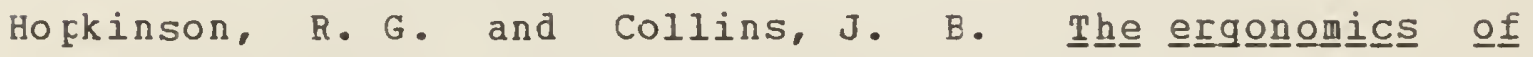
lighting. London: MacDonald, 1970 .

IE S Daylighting Committee, Recommended practice of

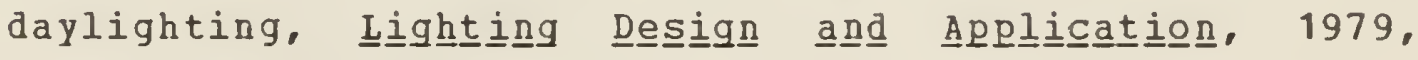
FEtruary, 25-60.

Le rons, T. M. and Robinson, A. V., Does visual clarity have meaning for IES illumination recommendations for task

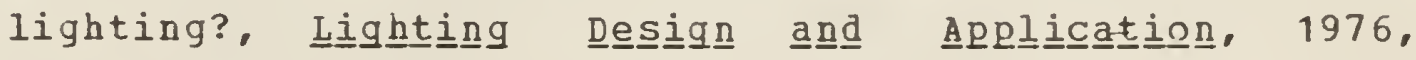
November, $24-30$ 
Lewin, I. and Griffith, J.W., Veiling reflection control

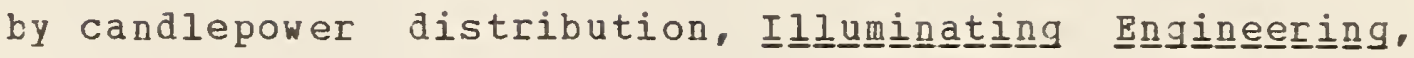
$1970,65(10), 544-601$

Lewin, I. and Griffith, J. W. The effect of illumination systems upon visual performance. In B. E. Foster (Ed.)

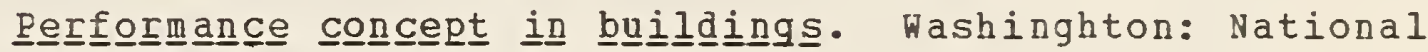
Bureau of Standaras (U.S.), Special publication 361, Vol 1. 1972.

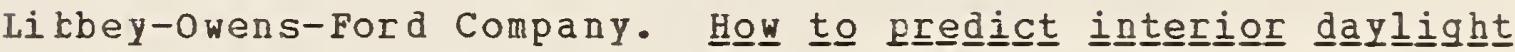

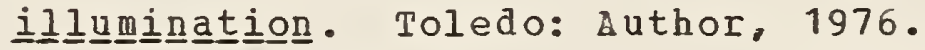

Licn, J. S., Richardson, E. and Browne, R. C., A study of the performance of industrial inspectors under two kinds

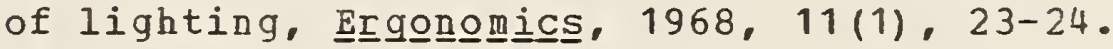

MCNelis, J. F., Human performance: a pilot study, 프므프믄

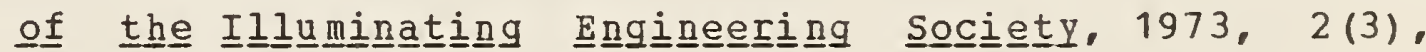
190-196.

Morse, R. M. and Litin, E. M. Postoperative delirium: a

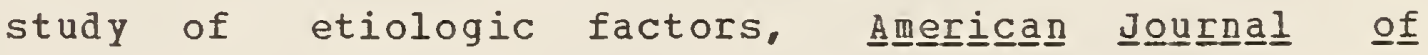

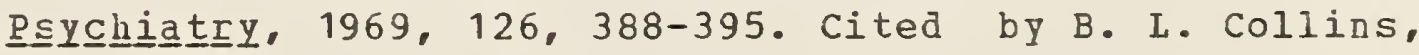

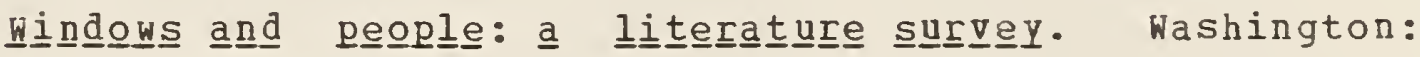
National Bureau of Standards, 1975, p28. 
Pangrekar, A. Relationship between illumination levels and visual performance, and the effect of age on visual performance. unpublished master thesis, Kansas state University, 1976.

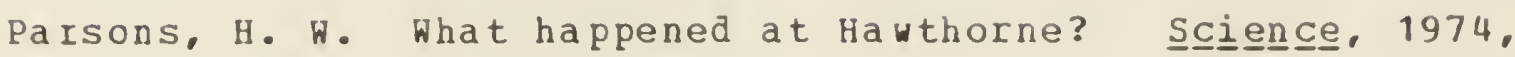
$183,922-932$.

Selkowitz, S., Effective daylighting in buildings, Lighthing

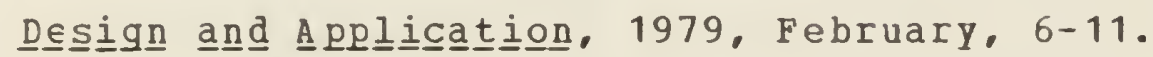

Selkowitz, S. Effective daylighting in buildings-Part 2,

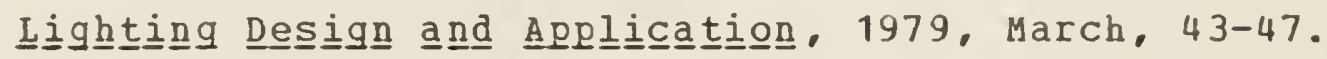

Smith, S. W.. Performance of complex tasks under different levels of illumination. Part I - Needle probe task,

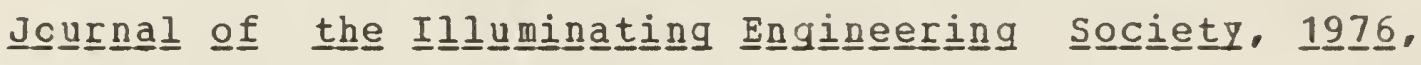
$\underline{5}(\underline{4}), \underline{2} \underline{3} \underline{5}=\underline{2} \underline{4} \underline{2} .1976,5(4), 235-242$.

Smith, S. W., Is there an optimum light level for office

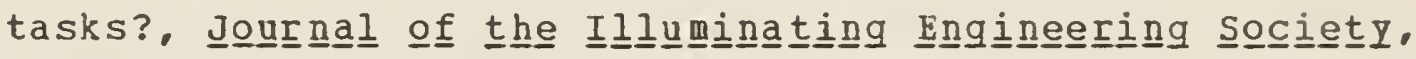
$1978,7(4), 255-258$.

Smith, S. W. and Rea, M. S., Proofreading under different

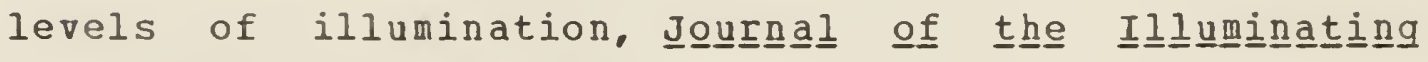

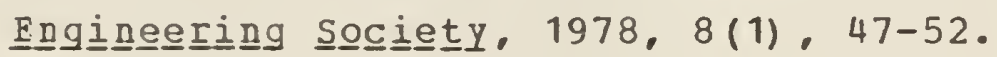


Thcrnton, W. A. and Chen, E., What is visual clarity?,

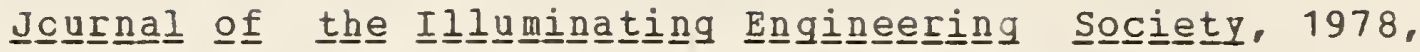
$7(2), 85-94$.

Walter, W., optimum lamp spectra, 프므므르 of

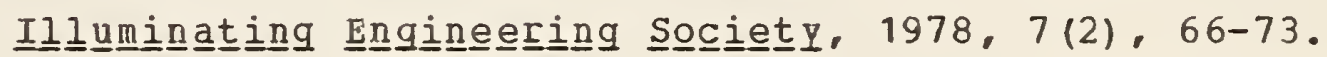

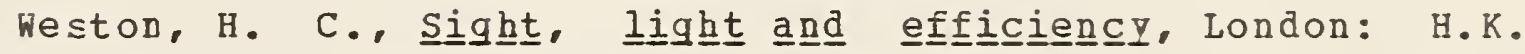
Lewis, 1949.

Wilson, L. M. Intensive care delirium; the effect of outside

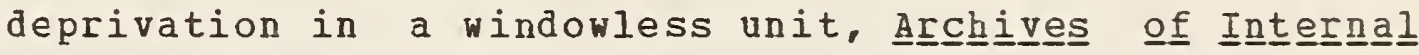

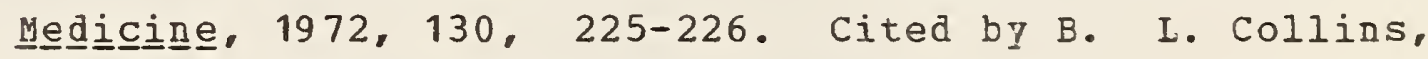

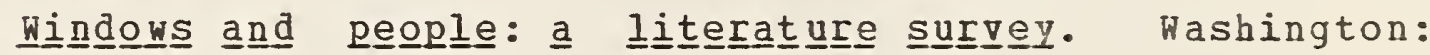
National Bureau of Standards, 1975, p29.

Wurtman, R. J., Effects of light and visual stimuli on endocrine function. In L. Martini and W. F. Ganong

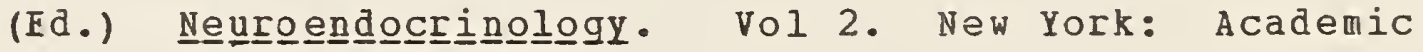
Press, 1967, 19-59.

Wurtman, R. J., Biological implications of artificial

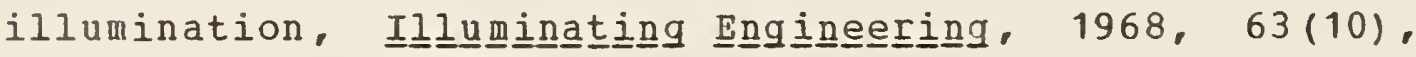
$523-529$.

Wurtman, R. J., Biological considerations in lighting environments, p므ogress 


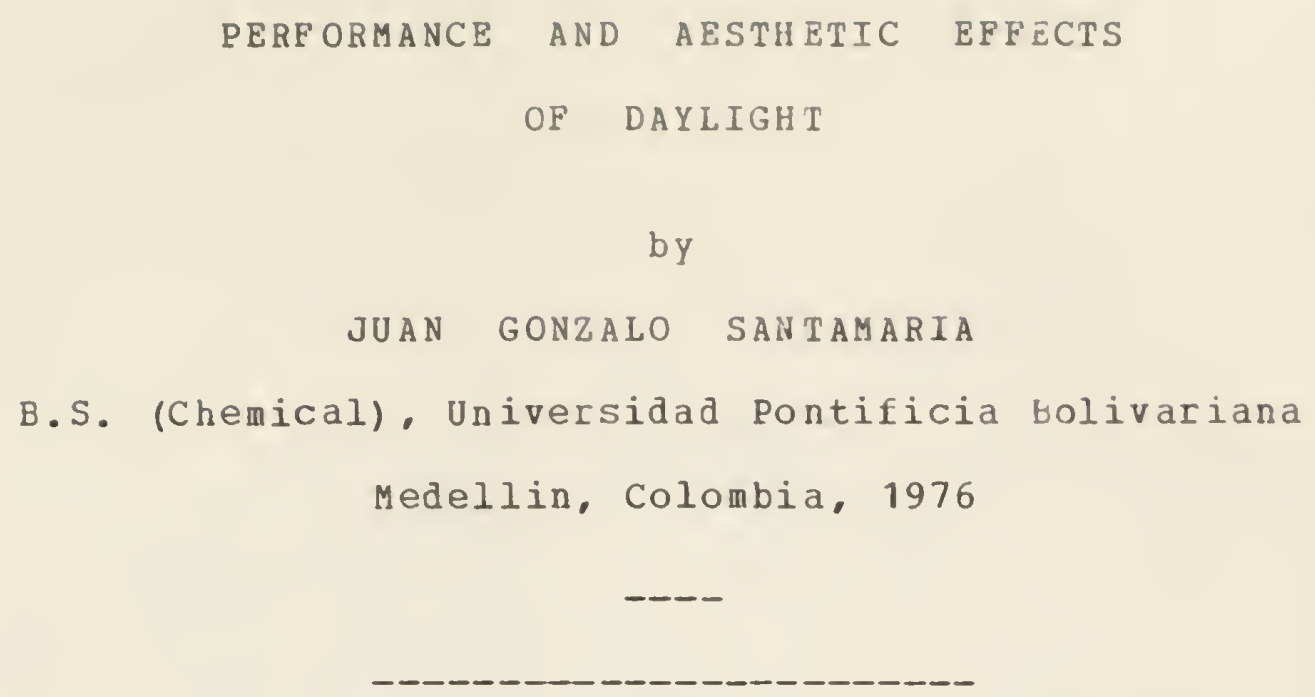

AN ABSTRACT OF A MASTER'S THESIS

submitted in partial fulfillment of the requirements for the degree

MASTER OF SCIENCE

Department of Industrial Engineering

KANSAS STATE UNIVERSTTY

Manhattan, Kansas 
The purpose of this research was to evaluate daylight as a source. It was compared with cool white fluorescent for the performance of practical visual tasks. Further, the semantic differential technique was used to measure user impressions. The three tasks used were needle probing, graph reading and proofreading; time was used as a measure of performance. subject's difficulty ratings were also recorded. Subjects performed the tasks in a lighting booth, flat white inside, allowing illumination to come from the top or the side. Four different conditions were employed (two sources, two angles) at one illumination level; varying illumination level between subjects, from 30 to 80 foctcandles.

The results of the graph reading and proofreading tasks shcw angle as a significant effect; the means favor sidelighting over toplighting. Source was significant for the proofreading task, interacting with the angle and the illumination level.

subject differences were significant. Illumination level was confounded with subject effects, due to the small range used, and the fact that subjects performed under one illumination level.

Factor analysis was carried on the semantic scales; the five factors extracted differ from those given by previous research. This difference was attributed to the performance oriented set-up. subject differences were again significant, and so was source; in general, daylight was 
preferred, and, particularly it was found less glaring and more colorful than fluorescent light.

In conclusion, subjects preferred daylight; however, it is not better than fluorescent for performance. Sidelight was better than toplight for the performance of flat tasks. Future research should consider the dimensional characteristics of the tasks, different sources, wider range of illumination levels. A different set-up is recommended for the aesthetic evaluations, as well as the inclusion of colors. 
